\title{
La cerámica feudal entre mediados de los siglos XIII y XIV, según el repertorio de la plaza de la Judería de Teruel ${ }^{\star}$
}

\author{
(Feudal pottery between mid-thirteenth and mid-fourteenth centuries, \\ according to the code of the square of the Jewish Quarter of Teruel)
}

\author{
Antonio Hernández Pardos *
}

\begin{abstract}
RESUMEN
La excavación arqueológica realizada en 2004 en la plaza de la Judería de Teruel aportó una sólida estratigrafía, que ha permitido reconocer un capítulo en la evolución de la cerámica utilizada en el sur de Aragón entre 1250 y 1350, aproximadamente. A partir de la adaptación de técnicas y recipientes previos, se fue configurando un nuevo repertorio cerámico para la sociedad feudal que se estaba consolidando tras la conquista del Levante peninsular.
\end{abstract}

Palabras clave: cerámica feudal, Teruel, cerámica almohade, contexto postconquista.

Cualquier planteamiento del discurso histórico que se proponga analizar el desarrollo de la formación social feudal en la Península Ibérica pasa, irremediablemente, por enfrentarse con la cultura material -a veces algo incomprendida-, obtenida a partir de la rigurosa práctica arqueológica. No hay que insistir mucho a la hora de considerar las manufacturas, especialmente la cerámica, como uno de los mejores exponentes de estos cambios socioeconómicos, teniendo en cuenta su alto grado de conservación. Es desde esta óptica en la que debe ser contextualizado este trabajo. No solo se trata de una simple taxonomía -examen, por lo demás, totalmente necesario

\begin{abstract}
The archaeological excavation in 2004 in the square of the Jewish Quarter of Teruel provided a solid stratigraphy, which has allowed us to recognize a chapter in the evolution of the ceramic used in the south of Aragon between 1250 and 1350, approximately. From the previous adaptation techniques and containers, was setting up a new utensils for feudal society was consolidating after the conquest of peninsular Levante.
\end{abstract}

Keywords: feudal ceramics, Teruel, Almohad ceramic, postconquest context.

si se quiere analizar un determinado registro-, sino de un discurso histórico que permita recorrer un camino, hasta el momento poco trillado, inverso al propio proceso histórico. Esta trayectoria debería conducir al lector desde los artefactos recuperados en una determinada estratigrafía arqueológica hasta las relaciones de producción que genera cada conjunto. En este sentido, son los contextos cerámicos recuperados en la ciudad de Teruel, concretamente bajo el vial de la plaza de la Judería, los que permiten plantear varias cuestiones en torno a esta sociedad como demandante de productos manufacturados, en este caso cerámicos ${ }^{1}$.

\footnotetext{
* La línea de investigación a la que pertenece el presente artículo ha sido beneficiada de una ayuda económica por el Plan General de investigación de Patrimonio Cultural del Gobierno de Aragón en 2008-2009 (HERNÁNDEZ, 2010).

** Arqueólogo profesional, ACRÓTERA Gestión del Patrimonio.

1 El análisis de todo lo relacionado con la elaboración de la vajilla, tanto desde el punto de vista de la cadena operatoria como de la lectura cultural de los sistemas decorativos, será desarrollado en otros trabajos.
} 


\section{INTRODUCCIÓN}

La empresa bélica desarrollada en el extremo meridional del valle del Ebro a lo largo del siglo XII condujo progresivamente a la transformación de amplios territorios y poblaciones, que acabarían quedando englobados en la Corona de Aragón. El punto de partida se sitúa, por lo tanto, en el período que sucede a la conquista de la Extremadura aragonesa a partir de la fundación de la villa de Teruel hacia 1170 por Alfonso II. A lo largo del siglo XII, el territorio situado al sur del Ebro en su sector central, va a ser objeto de la progresiva desestructuración y eliminación de la sociedad andalusí, bajo el empuje de nuevos contingentes de población feudal. La creación de la villa de Teruel estuvo destinada a convertirse, tanto en avanzadilla hacia la tan deseada Valencia almohade, como en el centro del proceso colonizador, ahora que el monarca se vio amenazado por la competencia del recién creado señorío de Albarracín, en manos de un noble de origen navarro.

Apenas conocemos las consecuencias materiales de los cambios sociales producidos como resultado de la conquista aragonesa, pero resulta innegable que el proceso de expansión feudal tuvo como resultado el desmantelamiento de la sociedad andalusí. Esta cuestión ha quedado adecuadamente planteada por Antonio Gargallo (1997), y recientemente retomada por Julián Ortega (2002), cuyas lecturas constituyen la base de este trabajo. A grandes rasgos, se empieza a reconocer una considerable despoblación y un empobrecimiento de la población que queda, en suma el desmoronamiento del sistema productivo -agrícola, manufacturero y comercial- y administrativo que existía. Sin embargo, esta dinámica parece que resultó lenta e inestable hasta que no culminó la conquista de Valencia. La toma de la ciudad y de su extenso territorio en 1245 debe considerarse fundamental a la hora de analizar el desarrollo del proceso feudal, y su repercusión en la cultura material. Las consecuencias de la conquista aragonesa en el área levantina, con la desarticulación del Sarq al-Andalus y la feudalización del nuevo Reino de Valencia, han sido ampliamente estudiados y desde diferentes ópticas por autores como Antoni Furió, Enric Guinot, Pedro Lópezy Josep Torró, entre otros, a cuya amplia bibliografía nos remitimos.

Tras la conquista de Valencia por los aragoneses, la población autóctona continuó poblando el territorio, aunque desplazada física y socialmente, tal y como queda perfectamente documentado en la ciudad, de la que fueron expulsados los andalusíes a favor de los colones para ser realojados en nuevos arrabales (TORRÓ, 1999, 2003). Este es, quizás, uno de los rasgos que definen la colonización del territorio levantino frente a la que se llevó a cabo en la Extremadura aragonesa o Cataluña la Nueva (GUINOT, 1997). A diferencia del caso valenciano, la creación de Teruel se lleva a cabo ex novo, no solo sin núcleo de población previo, sino sobre un territorio dominado por el despoblamiento. Al respecto, si bien se desconoce desde un punto de vista arqueológico la primera etapa del nuevo núcleo de población, otros enclaves rurales permiten reconocer un panorama de vacío demográfico que costó mucho repoblar. El panorama de la cultura material entre finales del XII -tras la fundación de la villa-y el último tercio del XIII -el inicio de la expansión de la ciudad y de su industria alfarera- permanece todavía sin aclarar ${ }^{2}$. Es en este horizonte - cubierto por una casi permanente niebla invernal- en el que debe situarse el inicio de esta travesía.

\section{LA PLAZA DE LA JUDERÍA DE TERUEL}

Dentro del casco urbano de Teruel, la actual plaza de la Judería se sitúa en el extremo oriental del caserío medieval, junto a la línea de la muralla y al llamado castillo menor, ocupando una suave ladera. En sus inmedia-

\footnotetext{
2 Es probable, sin embargo, que este vacío se vaya colmando gracias al castillo de Albarracín, cuyo contexto material está en vías de estudio a partir de los trabajos arqueológicos desarrollados en 2004-2006 por el que subscribe (HERNÁNDEZ, 2010).
} 
ciones se localizan la iglesia de San Pedro, el portal de Zaragoza y la plaza del mercado (actualmente, del Torico) (Fig. 1).

Fue en el año 1979 cuando se puso al descubierto bajo el vial de la plaza de la Judería, situada en el sector más elevado de la ciudad, un enorme espacio subterráneo construido mediante arcos apuntados (Lam. 1). Rápidamente, estos restos fueron identificados con una de las sinagogas con las que contaría la aljama turolense, aunque esta interpretación está descartada hoy día. Al descubrimiento de este célebre espacio, se sumó la publicación de un conjunto de lámparas rituales judaicas, elaboradas en cerámica y de cronología bajomedieval (ATRIÁN, 1979, 1981), provocando ambos hallazgos el "despertar" de la judería medieval de Teruel. Sin embargo, no va a ser hasta 2003 cuando se inicie la excavación arqueológica sistemática del conjunto urbano situado en su subsuelo de la plaza. Los resultados obtenidos en $2004^{3}$ permitieron reconocer el enorme potencial histórico de

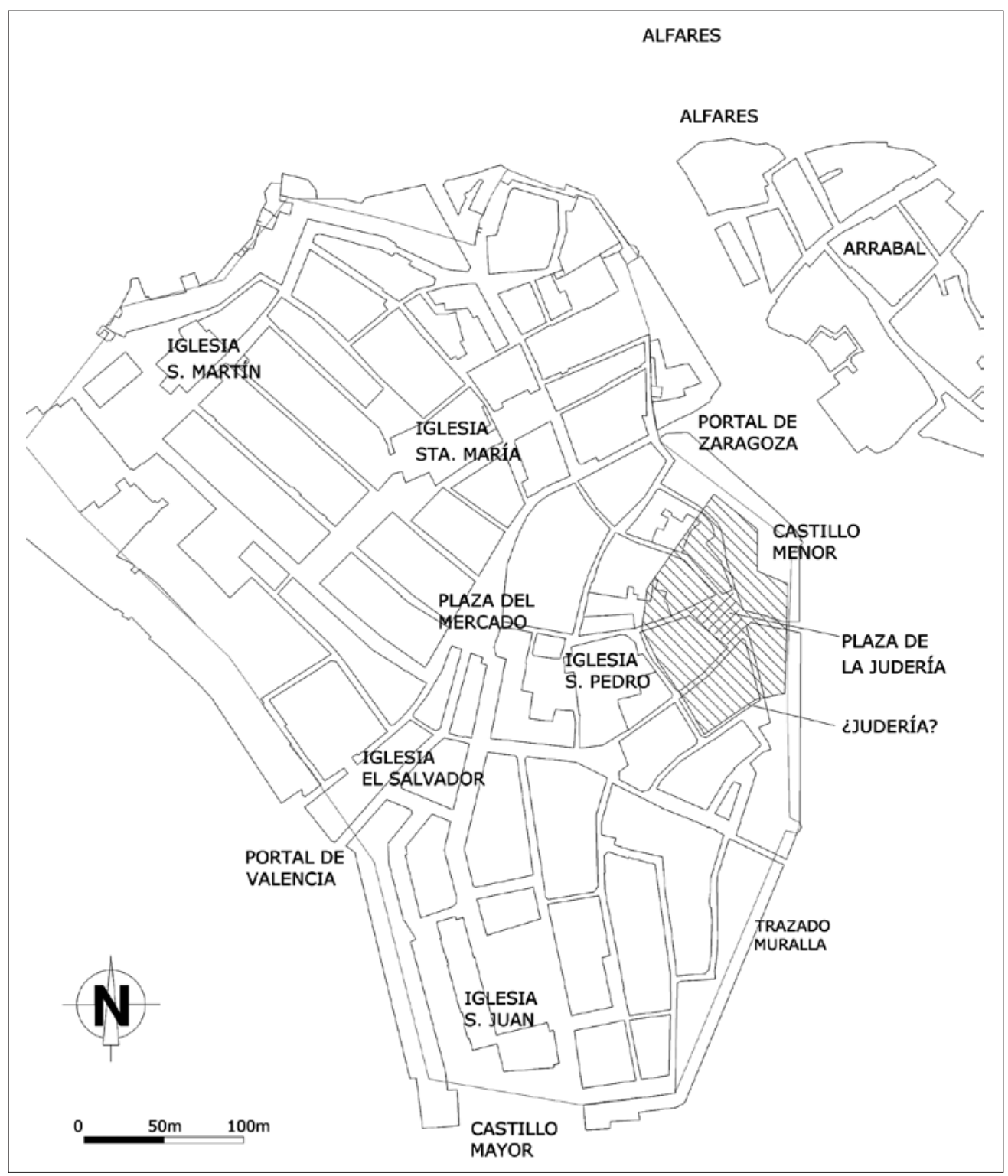

Figura 1. Plano del Teruel medieval, con la localización de la plaza de la Judería

3 La última fase de esta intervención arqueológica fue dirigida por Raquel Monteagudo y el que subscribe, responsabilizándose la primera de la precisa documentación estratigráfica llevada a cabo. 


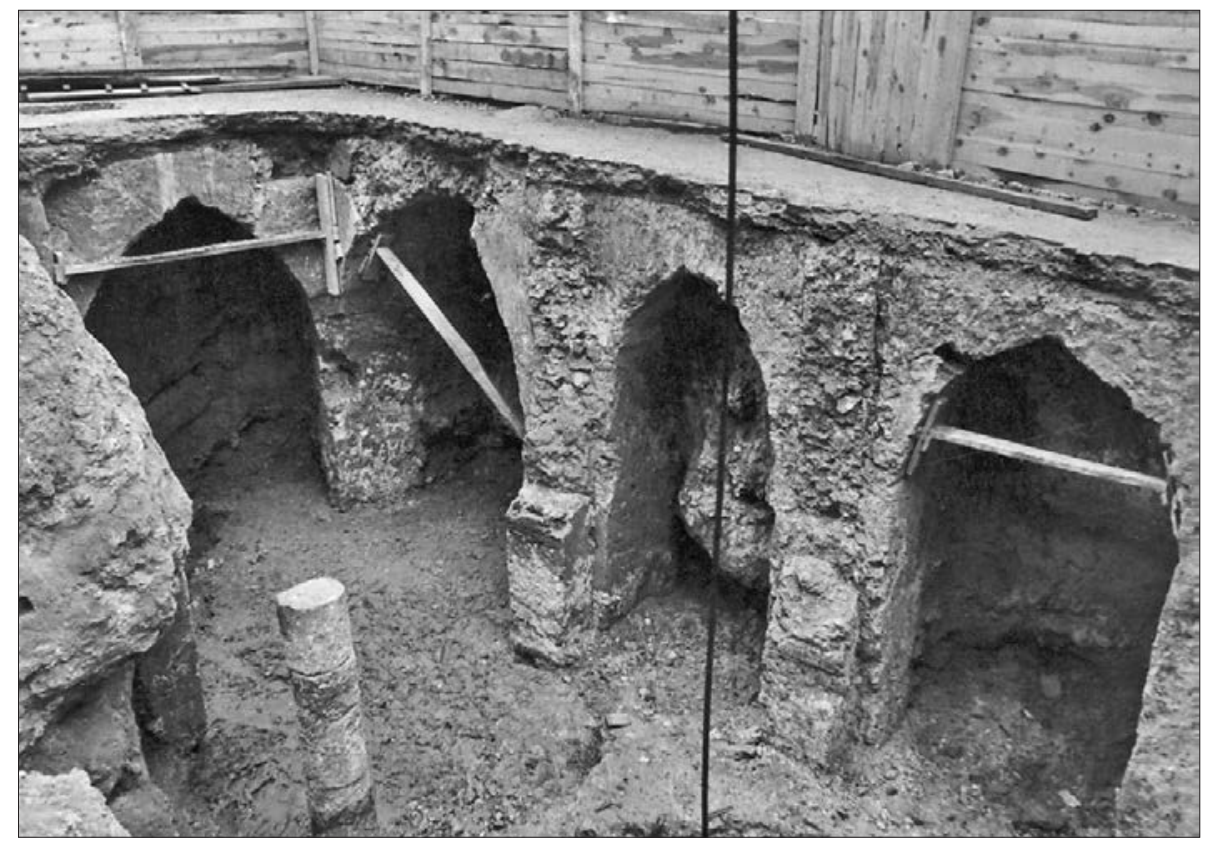

Lámina 1. Vista

de la gran bodega o espacio A-1 de la plaza de la Judería de Teruel, perteneciente a la actuación de 1979. Imagen cedida por el Museo de Teruel.

los restos, puesto que han permitido trazar un fragmento de la evolución de esta villa feudal ${ }^{4}$ (HERNANDEZ, en prensa) (Fig. 2). A continuación se describe, de uno modo simplificado, la estra- tigrafía documentada, incidiendo en aquellos aspectos que nos permiten situar estratigráficamente los depósitos de los que procede el material cerámico estudiado (Fig. 3).

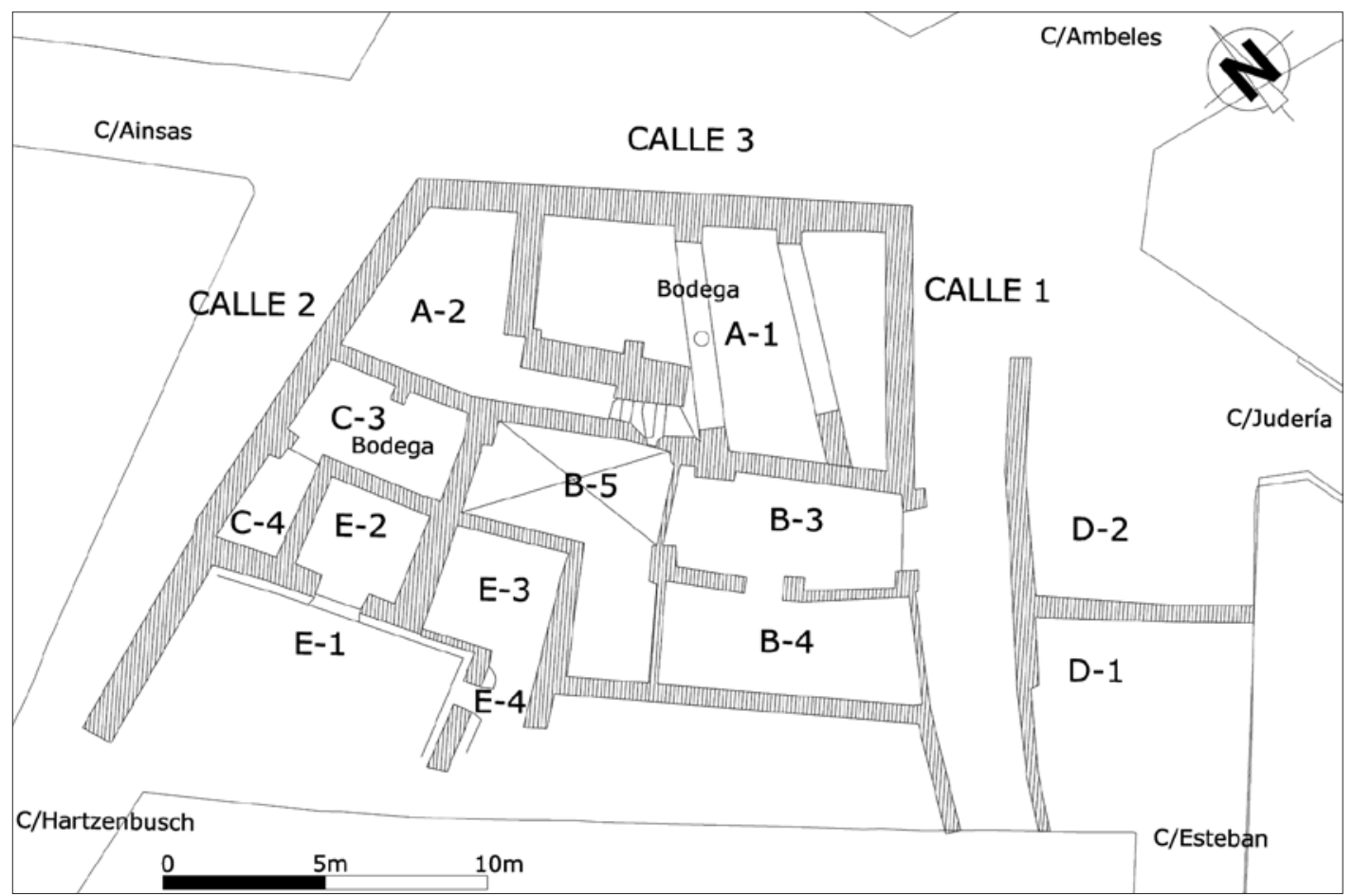

Figura 2. Planta con los espacios arqueológicos hallados en la plaza de la Judería de Teruel

4 Durante 2010 y 2011 se ha llevado a cabo un estudio en profundidad del conjunto arqueológico de la Plaza de la Judería, proyecto que contó con una ayuda financiera desde el XXVIII Concurso a la investigación del Instituto de Estudios Turolenses (HERNANDEZ, 2011, en prensa). 


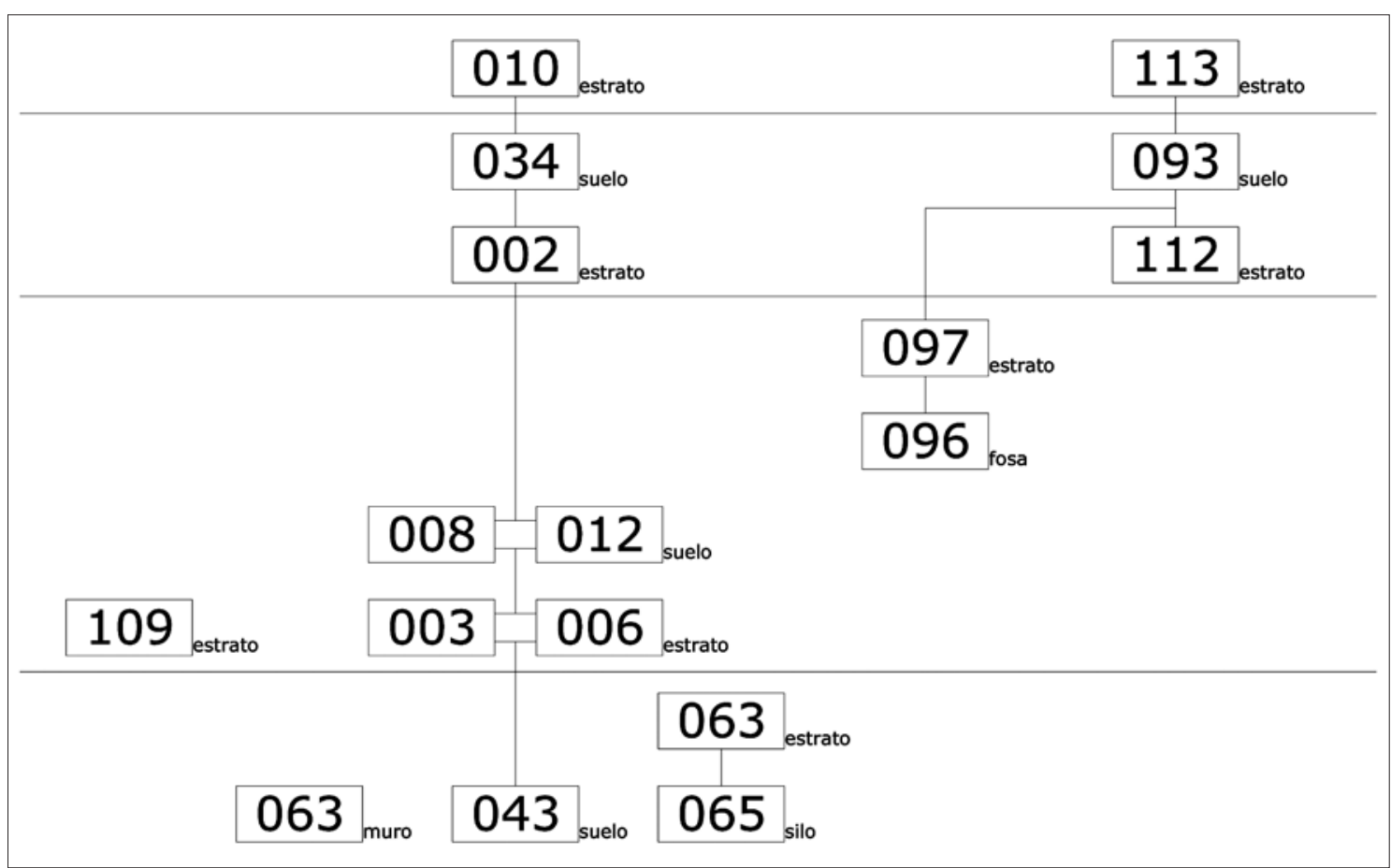

Figura 3. Secuencia estratigráfica (simplificada) de la plaza de la Judería de Teruel

La primera fase de ocupación presenta unos espacios domésticos adaptados a la orografía del terreno, y caracterizados por un escaso desarrollo constructivo y una economía de medios. El elemento de mayor interés radica en la presencia de un silo subterráneo UE 065, amortizado por el depósito UE 063 y de donde procede la vajilla seleccionada para esta fase (Fig. 2, espacio B-4). El nivel estaba formado por una tierra limosa de carácter orgánico, y contenía un voluminoso conjunto cerámico, caracterizado por su homogeneidad y por el buen estado que presentan las piezas -muchas de las cuales se hallaron enteras-. Así, el silo acabó siendo reutilizado como un basurero doméstico, en donde fue desechado y arrojado el ajuar cerámico existente en la vivienda una vez que ésta quedó abandonada o fue reocupada.

La segunda fase de ocupación arranca con la transformación urbanística y constructiva del sector, arrasándose las construcciones preexistentes y trazando nuevas viviendas. En este momento se configura el esquema urbanístico del sector, con pavimentos de yeso y muros de argamasa encofrada. Son los depósitos de escombro UE 003, 006 y 109 -sobre los que se forman los nuevos suelos- los que han proporcionado la vajilla de esta fase ${ }^{5}$ (Fig. 2, espacio B-4). El material cerámico es, desde un punto de vista estratigráfico, inmediatamente anterior a la construcción de las viviendas. A partir de este momento, los esquemas arquitectónicos y sistemas constructivos utilizados con anterioridad van a ser definitivamente sustituidos por otros nuevos, introduciéndose la argamasa de yeso como mortero base. No obstante, será la propia transformación lo que demuestra la existencia de mayores recursos económicos, dinamismo social y una planificación del espacio. Teniendo en cuenta las fuentes escritas, a lo largo de la segunda mitad del siglo XIII parece consolidarse una comunidad judaica en Teruel, que se asentará en este sector del caserío a los pies del castillo menor.

5 Al no corresponder a niveles de uso/abandono que contienen conjuntos cerámicos primarios, la cerámica presenta un estado fragmentario, constituyendo una muestra menos representativa de la vajilla del horizonte II. 
En la tercera fase de ocupación, se excava la fosa UE 96, la cual quedará amortizada por el depósito UE 97, que ha proporcionado un enorme y homogéneo conjunto cerámico (Fig. 2, espacio D-2). Se trataría de un depósito cerrado, primario, presumiblemente formado por el ajuar cerámico existente en la vivienda. A partir del siglo XIV la actividad constructiva es continua en este sector de la ciudad, quedando definidos los tramos de tres calles, con un esquema urbanístico de carácter radial. De las cinco viviendas identificadas, dos de ellas se dotan de grandes espacios en planta subterránea excavados en la roca que sirven de bodega, con potentes estructuras encofradas de tapial formando arcos apuntados.

\section{EL REPERTORIO CERÁMICO ESTUDIADO *}

El conjunto cerámico recuperado en los tres primeros horizontes ${ }^{6}$ de la plaza de la Judería constituye un buen escaparate a través del cual se puede reconocer la evolución del repertorio cerámico demandado por la sociedad turolense (HERNANDEZ, 2010, 2011). Huelga decir que este repertorio responde a una demanda específica: la de una determinada población que ocupó este sector del caserío turolense. Sin embargo, detrás de esta afirmación, se esconde el complejo marco analítico de los mecanismos que configuran la demanda: desde los modos de distribución y comercialización hasta los hábitos y sistema cultural de los consumidores, que supera, desde luego, las limitaciones de este trabajo. Por ello, solamente la investigación y publicación de otros conjuntos estratigráficos que se sumen a éste permitirá obtener un panorama más ajustado y preciso. La identificación de los diversos recipientes puede consolidar una base documental, en este caso material, que permita extraer aspectos más estructurales como la producción, distribución y consumo cerámico, que contribuyan a entender el largo y complejo proceso de formación de la sociedad feudal de los siglos XIII y XIV en la Extremadura aragonesa.

\section{Fase I (ca. 1245-1280)}

Dentro del repertorio cerámico destinado a la elaboración de alimentos en la Fase I, se han identificado dos tipos de recipiente: olla y cazuela. Durante esta etapa, el menaje culinario está formado fundamentalmente por ollas globulares de cierto tamaño, con cuellos cortos diferenciados en el hombro por una escotadura y rematados por bordes engrosados.

-Olla I (Fig. 4. 1). Corresponde a un recipiente de tamaño medio caracterizado por un borde moldurado. Los paralelos proceden de contextos arqueológicos feudales más septentrionales, con recipientes de cuello vuelto sin diferenciar elaborados mediante cocción reductora. Así, en varios asentamientos fortificados aragoneses vinculados con la temprana colonización aragonesa se han recuperado ejemplares con un modelado del borde no tan desarrollado, como en Torrecid (MARTínEZ, 1991: PP. 47-56, LAM 1, 4-5, 7-1), Los Castellares en Herrera de los Navarros y el castillo de Alcañiz (ORTIZ, 1995: FIG. 4). No obstante, la semejanza más evidente se obtiene en conjuntos del área catalana con diversas variantes, siendo el modelo de olla predominante en la ciudad de Tarragona durante la segunda mitad del siglo XIII (MACIAS et alii: p. 74, fig. 10-13), aunque también aparece en el entorno de Barcelona (RIU y RIU, 1995: fig. 12.4). La afinidad entre ambos modelos muestra claramente la utilización de este modelo de olla gris usado en tierras feudales más septentrionales, y su pervivencia en la frontera aragonesa.

-Olla II (Fig. 4. 2). Este modelo de olla muestra un cuello con borde engrosado, de perfil casi rectangular. Presentaría grandes dimensio-

\footnotetext{
* Los dibujos de las piezas cerámicas han sido realizados por Jesús G. Franco, Raquel Monteagudo y el autor en 2004 y 2008 . Las fotografías de las mismas han sido realizadas por Cristina Bazán en 2008.

6 La horquilla cronológica que enmarca al análisis de cada etapa es aproximada, y responde a la estratigrafía de la plaza de la Judería de Teruel. Los materiales seleccionados representan fielmente la variedad tipológica de cada horizonte, reservándose el estudio estadístico para otro momento.
} 


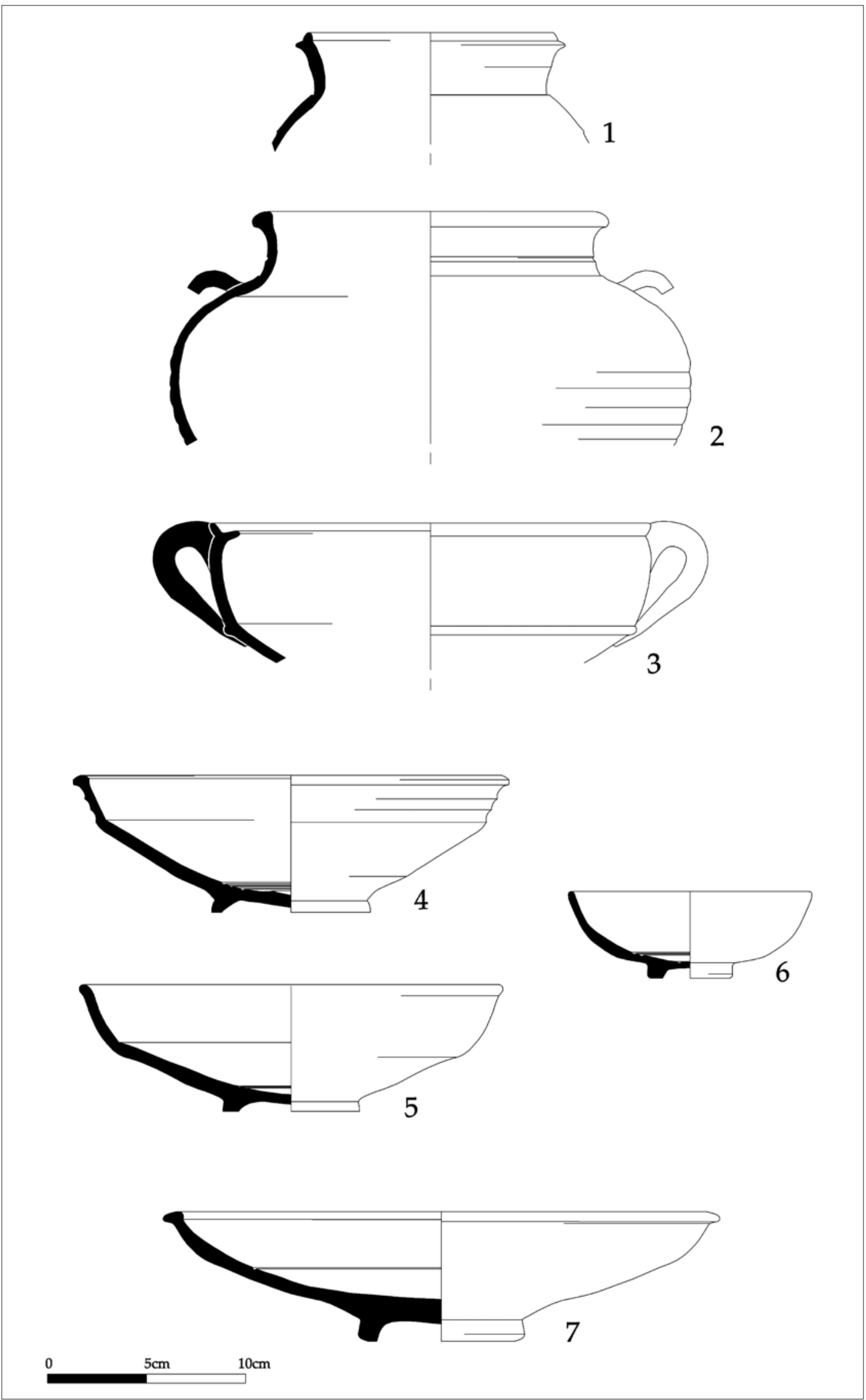

Figura 4. Repertorio cerámico de la plaza de la Judería de Teruel. Fase l: cocina y vajilla barnizada 
nes, con una boca de mayor tamaño que el resto de piezas. Los contextos materiales postconquista de la ciudad de Valencia -que se están empezando a publicar- proporcionan varias ollas semejantes (MARTí et alii, 2007: p. 38, lam. 10, tipo 4 y 8). Este recipiente de cocina irá evolucionando, haciéndose mayoritario en los contextos urbanos de Teruel del siglo XIV.

En lo referente a la cerámica culinaria, el repertorio se completa con un interesante ejemplar de cazuela (Fig. 4.3), un recipiente de grandes dimensiones. Desde el punto de vista morfológico, el recipiente se caracteriza por dos rasgos fundamentales: una carena baja moldurada mediante un baquetón y un borde bífido con el labio interior muy desarrollado. Se completaría con dos asas -al menos- en cinta.

El paralelo más claro y cercano de esta pieza corresponde a las cazuelas de época almohade difundidas por el Levante peninsular. Sin embargo, el interior de estas piezas está cubierto por un barniz. Así se ha documentado abundantemente en el casco urbano de Valencia y entorno (AZUAR, 1995: pp. 78-79; AZUAR, 1994: f. I.8; BAZZANA, 1980: no 103-109; COLL et alii, 1988: no 12), en algunos casos bien contextualizados y fechados entre finales del siglo XII y el primer tercio del XIII. Este tipo de cazuela continuó elaborándose tras la conquista de Valencia, distinguiéndose en contextos de colonización un modelo similar aunque sin cubierta esmaltada (MARTí et alii, 2007: pp. 39-40).

Obviando el caso de la cazuela, que probablemente sea una imitación directa del recipiente almohade, las ollas no parecen tener ningún vinculo con la vajilla hasta entonces elaborada, aspecto de parece indicar la existencia de un cambio en el proceso culinario y, mejor, una adaptación de los alfareros a la demanda.

Pasando a analizar la vajilla ${ }^{7}$, diferenciaremos entre el grupo formado por las piezas abiertas destinadas a servir o tomar la comida -con y sin cubierta vidriada-, y las formas cerradas para la contención de líquidos, las cuales presentan un acabado simplemente bizcochado. Así, dentro del repertorio para mesa, se han diferenciado cuatro piezas: plato, escudilla, cuenco y altamía, los dos primeros con cubierta barnizada. El tipo mejor representado corresponde al plato, forma abierta que procede directamente del ataifor del repertorio andalusí, del que era la forma abierta más extendida.

El plato I (Fig. 4. 4) se caracteriza por su perfil carenado y moldurado, que finaliza en un labio horizontal. Se completa con tres molduras bajo el borde, y con una decoración incisa al interior, formando varios círculos concéntricos en el fondo. Presenta un acabado vidriado monócromo de color verde marronáceo al interior, obtenido gracias a coloración grisácea de la pasta por una cocción reductora.

Dentro del contexto almohade, se reconoce cierta vinculación con ejemplares recuperados en la plaza de la Almoina de Valencia, de perfil carenado sin moldurar y cubierta barnizada al interior (COLL et alii, 1988: no 22 y 23). Sin embargo, las similitudes más claras hay que buscarlas en contextos postconquista, como corresponde al caso valenciano. Se trata de un recipiente de perfil abierto y carena alta redondeada, con un característico labio horizontal en el borde (ROSSELLó, LERMA, 1999: Fig. 4, 5114-4). Esta producción formaría parte de los primeros repertorios feudales posteriores a la conquista, apareciendo asociada con ollas grises importadas desde el área catalana, tal y como se viene comprobando en los últimos tiempos (MARTí et alii, 2008: p. 42, lam. 12). No obstante, el modelo de plato/ataifor mayoritario en estos contextos muestra un perfil carenado, más anguloso. En este caso, el tercio superior de la pared es vertical, rematado por un borde exvasado en forma de pico, por lo tanto, muy próximo al localizado en la Judería de Teruel. Del casco urbano de Paterna procede un ejemplar cubierto por un barniz melado, presumiblemente elaborado en los talleres locales

\footnotetext{
7 El término vajilla hace referencia exclusiva a las piezas y utensilios para el servicio de mesa, quedando excluidos los recipientes de cocina y almacenaje.
} 
(COLL et alii, 1988: nº5). El propio casco urbano de Teruel ha proporcionado otros ejemplares de idéntica procedencia, como el conjunto de la plaza San Juan (ESCRICHE, ORTEGA, 2002: no 12 y 13) y el castillo de Albarracín (ORTEGA, 2007B: no 284). Este tipo de recipiente aparece también en contextos arqueológicos postconquista de Lérida (LORIENTE, OLIVER, 1992: PP. 133-135).

El plato documentado en Teruel y Albarracín, seguramente elaborado en los alfares turolenses, guarda bastante relación con los modelos recuperados en ambientes postconquista. En todos estos casos se trata de una adaptación del modelo precedente almohade elaborado en el Levante.

Se ha identificado también una variante del plato I, con un perfil carenado suave rematado - a diferencia del anterior-por un simple borde redondeado y ligeramente engrosado (Fig. 4. 5). Presenta un acabado vidriado al interior de color verde, obtenido gracias a la coloración grisácea de la pasta por una cocción reductora. El paralelo más cercano lo hallamos en un tipo de ataifor elaborado en el primer tercio del siglo XIII, procedente de la plaza de la Almoina (COLL et alii, 1988: n²3).

Junto con el plato, los alimentos son servidos también en un recipiente más pequeño identificado como la escudilla I (Fig. 4. 6;
Lam. 2). Muestra un perfil hemisférico y borde redondeado. Como elemento decorativo presenta dos círculos concéntricos incisos en el fondo. La superficie interior está cubierta por un barniz de color marrón verdoso, obtenido gracias a coloración grisácea de la pasta por una cocción reductora. Con una anchura de $120 \mathrm{~mm}$ y altura de $43 \mathrm{~mm}$, representa la pieza esmaltada de menor tamaño del servicio de mesa. Sin paralelos claros, probablemente se trate de un nuevo recipiente derivado a partir de la adaptación de un tipo de ataifor almohade de perfil convexo. Ejemplares con idéntico perfil se han localizado en el entorno de Valencia, como el yacimiento de Santa Fe de Oliva (BAZZANA, 1986: p. 208, fig. 7.1).

El último modelo de recipiente abierto corresponde a una fuente (Fig. 4. 7). Presenta un perfil muy divergente, con borde engrosado formando un labio horizontal. Se completa con un pie anular muy grueso y alto. Muestra una decoración incisa al interior, a base de un círculo concéntrico a media pared y una espiral en el fondo. Sin duda alguna se trata de la forma abierta de mayores dimensiones de este conjunto, con un diámetro en boca de 270 mm y una altura de $65 \mathrm{~mm}$, algo menor que en los ataifores completos que hemos estudiado.

Este recipiente se aleja claramente de todos los ataifores de tradición andalusí,

Lámina 2

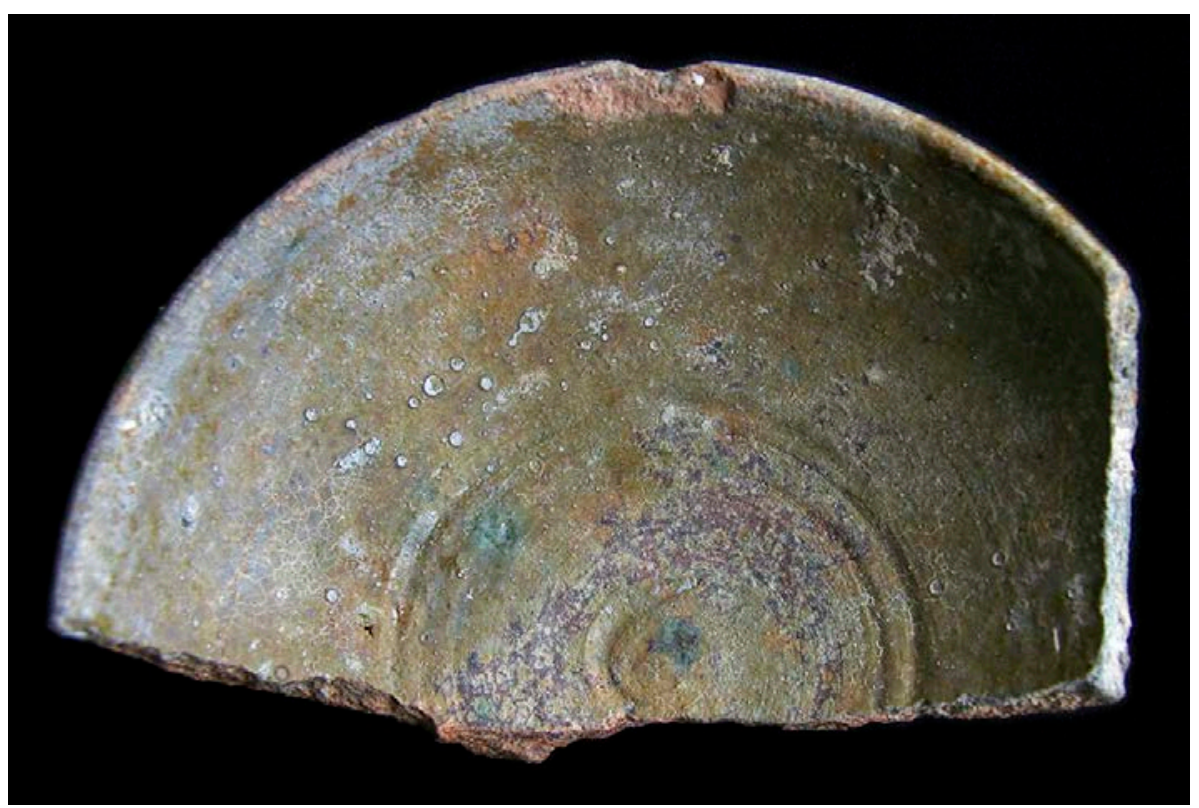


tanto de perfil carenado como hemisférico. No obstante, es posible que el recipiente derive de un tipo ataifor de grandes dimensiones documentado en Valencia en el primer tercio del siglo XIII (COLL et alii, 1988: no 25). De todas maneras, el repertorio bajomedieval más primitivo proporciona algún paralelo. Así, dentro de las tempranas producciones barnizadas elaboradas en el área barcelonesa, hallamos un tipo de tajador cuyo perfil es muy similar a la pieza turolense, recuperado en el convento de Santa Caterina y fechado con anterioridad a 1260 (HUERTAS, 2008: pp. 107-108). Es probable que podamos identificar esta pieza como un antecedente del tajador, recipiente de perfil muy abierto surgido de los alfares bajomedievales a partir de la primera mitad del siglo XIV, sobre todo de los turolenses.

Estas piezas de mesa vidriadas se ven acompañadas por otros recipientes sin cubierta: altamía y cuenco.

La altamía (Fig. 5. 8) corresponde a un modelo de cuenco profundo bien definido dentro del repertorio feudal turolense. Se caracteriza por un fondo ligeramente convexo, una carena alta y pared recta sin labio. Esta pieza es característica de las primeras producciones locales desde finales del XIII y durante la primer mitad del XIV, volviéndose minoritaria desde mediados de la centuria. Se trata de una incorporación al repertorio de la vajilla, seguramente inspirada en los recipientes de madera utilizados en latitudes más septentrionales (ORTEGA, 2002: pp. 145-146). Del casco urbano de Lérida proceden ejemplares de un tipo de recipiente que guarda bastante parecido. Fechado a partir del siglo XIII, muestra barniz al interior (LORIENTE, OLIVER, 1992: p. 143, t. V).

La última pieza destinada a la mesa corresponde a un cuenco (Fig. 5. 9). Muestra un fondo ligeramente cóncavo, una carena alta suavizada, y simple borde redondeado. Se completa con una pequeña asa de sección ovalada. De la Plaza de la Almoina en Valencia proviene un recipiente semejante al cuenco, quizás corresponda a su antecedente. Cubierto por un barniz al interior, muestra un perfil menos carenado, y está fechado entre finales del siglo XII y el primer tercio del XIII (COLL et alii, 1988: no 14). Del mismo casco urbano procede el paralelo más claro de la pieza turolense. Se trata de un recipiente con similar perfil, aunque el borde está decorado con dos acanaladuras al exterior, habiendo sido fechado tras la conquista aragonesa (ROSSELLó, LERMA, 1999: fig. 3, p. 5123-11).

A diferencia de lo observado con las ollas, en el caso de las formas abiertas para mesa las pautas de consumo son más complejas. En todo caso, esta vajilla pone de manifiesto su novedad respecto a lo que ocurría en el período precedente, habiéndose producido una selección aquellos recipientes o aspectos de los mismos que resultarían de interés al consumidor. Desde los centros alfareros, como Teruel, aquellos fueron sometidos a una notoria adaptación, no una simple imitación.

El repertorio de mesa para el servicio de líquidos está formado por los siguientes recipientes: jarro y taza.

El jarro (Fig. 5. 10; Lam. 3) se caracteriza por un cuerpo globular, de fondo convexo con el contorno anguloso y cuello alto cilíndrico sin labio. Se completa con un asa vertical de sección ovalada. La cultura material del primer tercio del siglo XIII en Valencia nos ha proporcionado un tipo de jarrita que bien podría considerarse un antecedente del jarro recuperado en la Judería turolense (COLL et alii, 1988: no 29). Se trata de un tipo de recipiente poco habitual en los contextos arqueológicos anteriores a la conquista del Levante. Sin embargo, es en tierras alicantinas donde hemos localizado los paralelos más notorios. Las excavaciones realizadas en el castillo de Torre Grossa (Jijona, Alicante) proporcionaron un interesante conjunto material, fechado a mediados de siglo (AZUAR, 1985: pp. 51-52, no 55, 56 y 57). Tanto desde un punto de vista morfológico, como por la ausencia de ninguna decoración, este grupo de jarritos se diferencia claramente del nutrido repertorio de recipientes almohades, por lo que es más probable que pertenezcan al horizonte postconquista de la fortificación. Por todo ello, resulta notoria la proximidad 

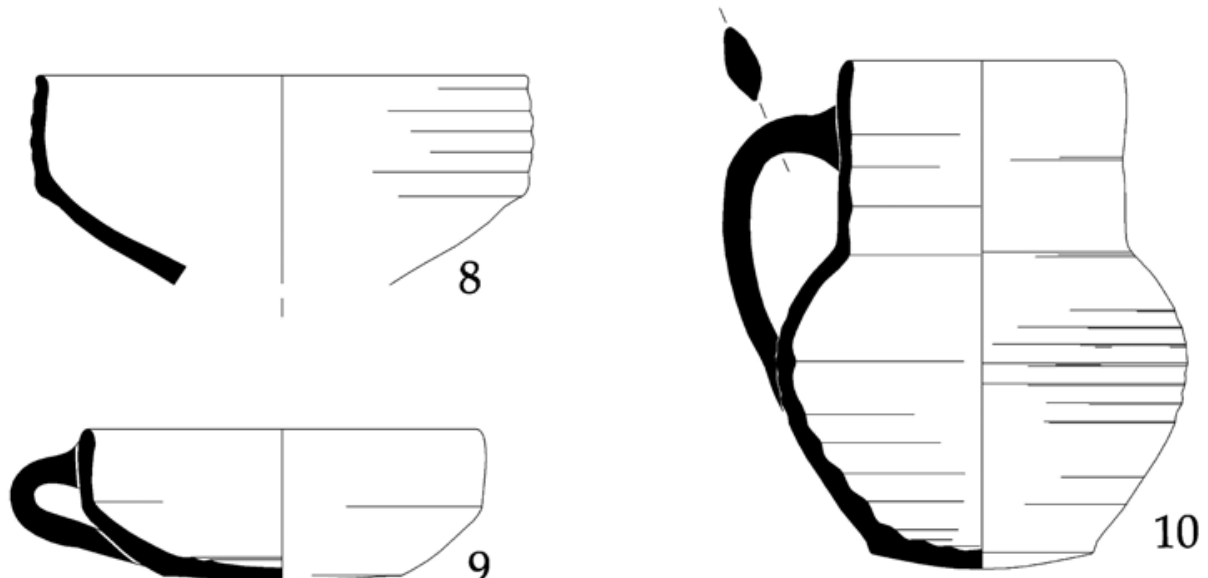

)
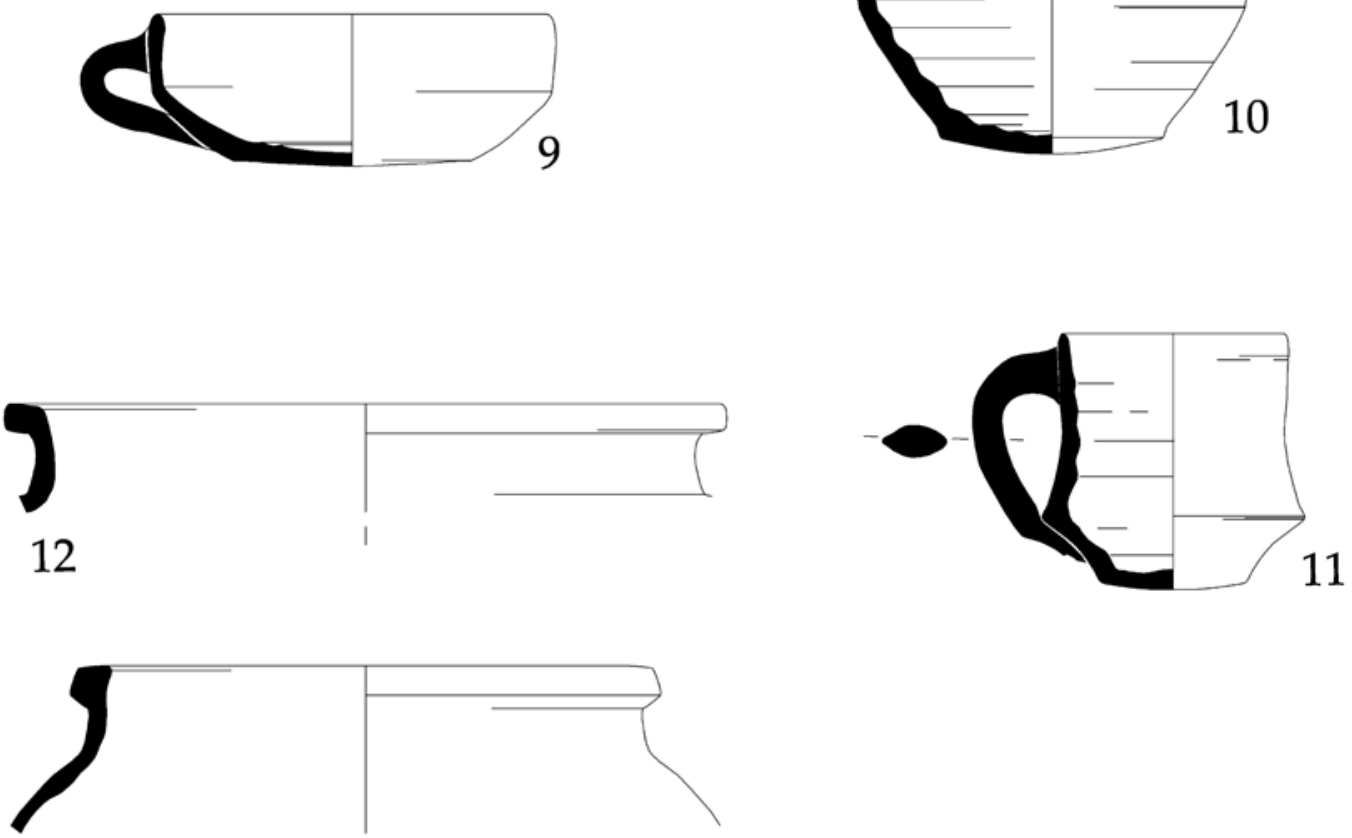

13

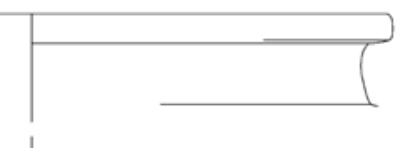

12
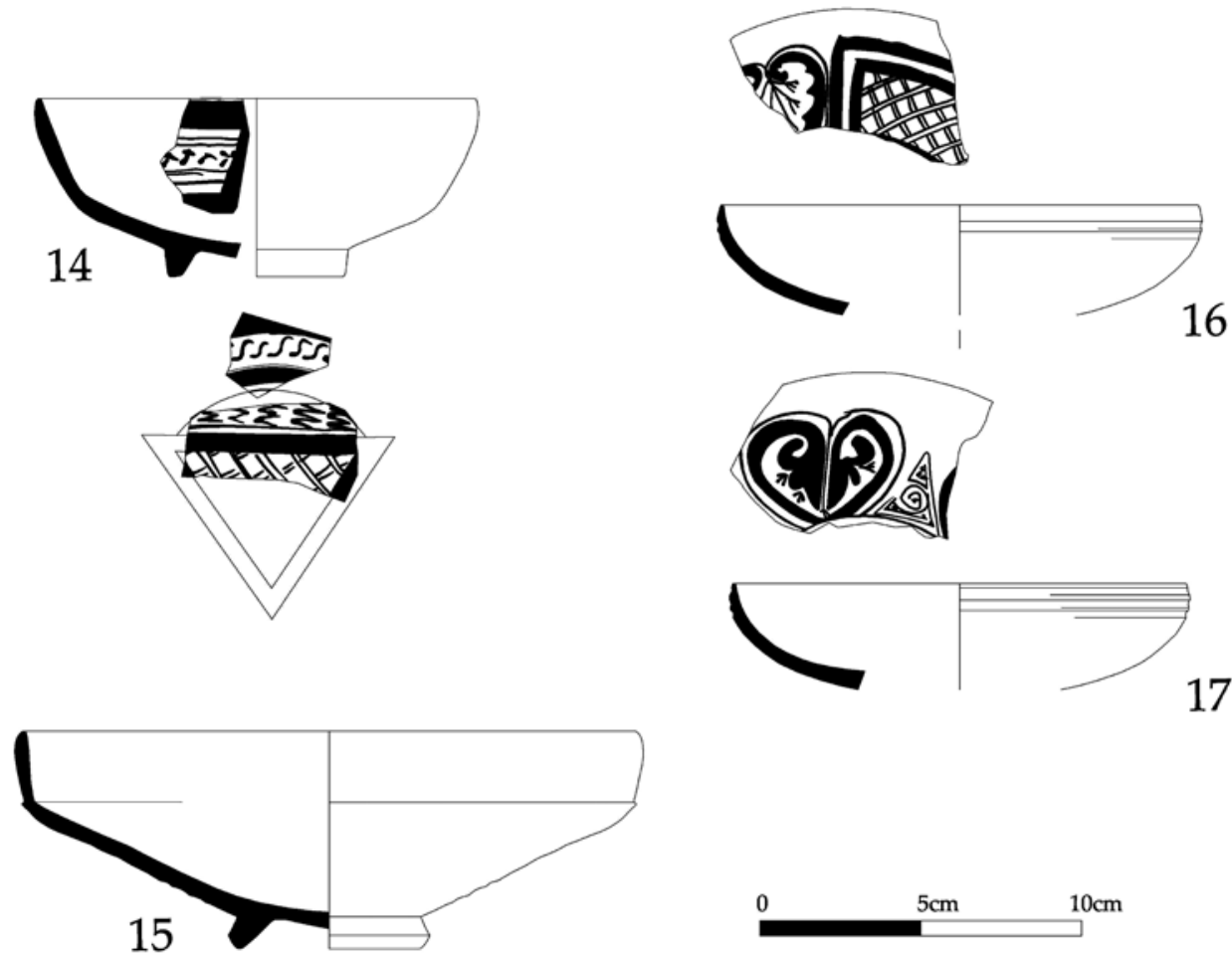

17

Figura 5. Repertorio cerámico de la plaza de la Judería de Teruel. Fase I: vajilla bizcochada; y Fase II: cocina y vajilla 


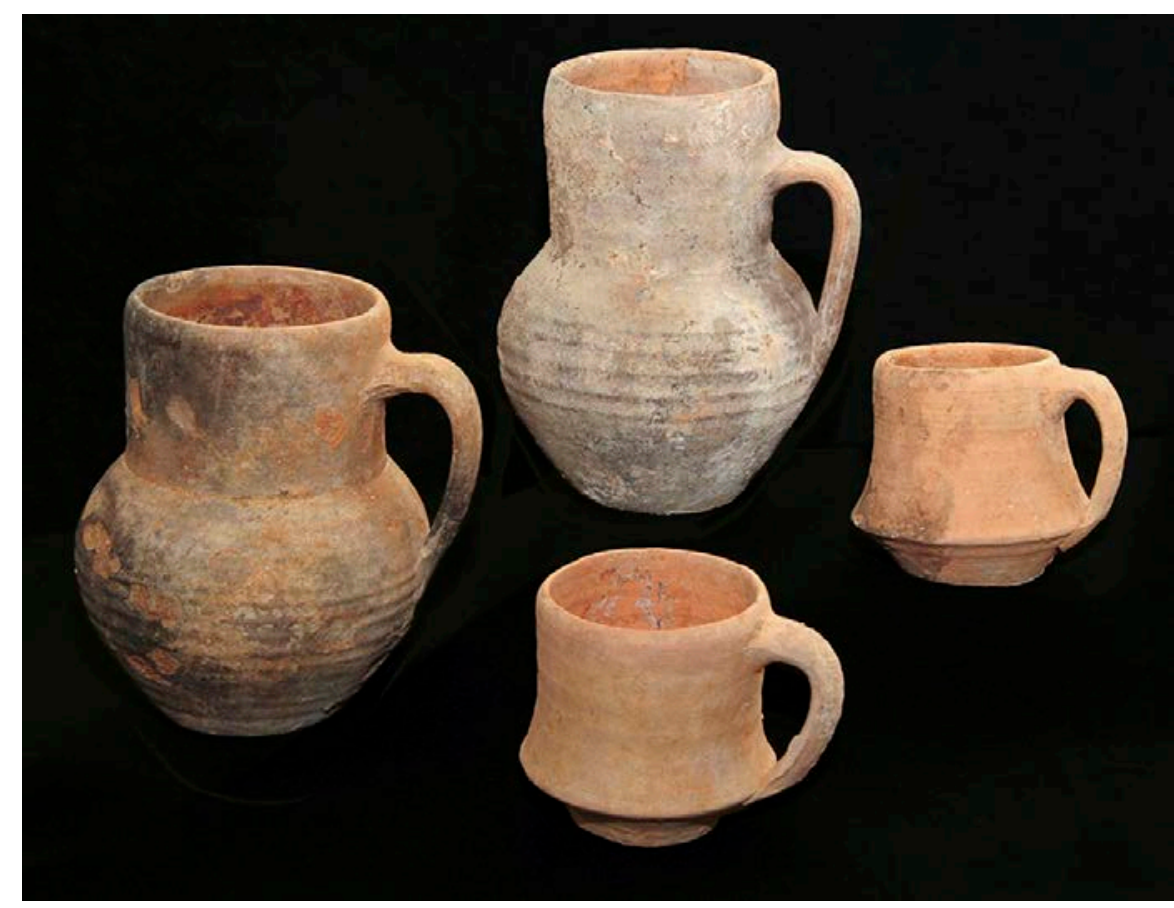

Lámina 3. Conjunto de dos jarros y dos tazas, Fase I morfológica del jarro recuperado en Teruel con el recipiente alicantino. Probablemente, el ejemplar almohade procedente del casco urbano de Valencia deba considerarse como el modelo que posteriormente los talleres feudales transformaron.

El siguiente tipo cerámico lo constituye la taza (Fig. 5. 11; Lam. 3). Se trata de un pequeño recipiente con carena baja apuntada, fondo ligeramente convexo y perfil cilíndrico con las paredes convexas y sin labio. Se completa con una única asa vertical de sección ovalada. De la plaza de la Almoina de Valencia proviene un tipo de recipiente sin cubierta vidriada, elaborado en el primer tercio del siglo XIII, que guarda cierto paralelismo con la pieza turolense (COLL et alii, 1988: no 31). Este mismo casco urbano ha proporcionado otro ejemplar de taza sin vidriar y fechado en el siglo XIV (COLL et alii, 1988: n 72). En este sentido, los parecidos que existen con la pieza tardoandalusí procedente de Valencia permite considerarlo como un claro antecedente de los ejemplares bajomedievales, valencianos y turolenses.

Este registro guarda cierta semejanza con el repertorio postconquista valenciano, diferenciándose claramente de los contextos tardoandalusíes levantinos del primer tercio del siglo XIII. La única excepción viene representada por la cazuela bífida, que se puede considerar claramente como una pervivencia de un modelo andalusí, sin embargo, de escasa trayectoria posterior. En líneas generales, tanto en la vajilla culinaria como en el servicio de mesa, se asiste a la incorporación de nuevos recipientes -tanto en su forma como en su acabado-, a partir de la adaptación de algunos modelos precedentes.

No hay duda de que, en comparación con el repertorio cerámico almohade, la vajilla destinada al servicio de líquidos constituye el grupo que más cambios experimenta con la feudalización. La jarrita, ampliamente elaborada por los alfares andalusíes con múltiples soluciones tipológicas y decorativas, prácticamente dejó de producirse tras la conquista cristiana. Esta importante variación en la vajilla -formada básicamente por un tipo de jarro alto y una taza con una sola asa- es un claro indicativo de la transformación social y culinaria ocurrida con el desarrollo de la sociedad feudal, con nuevas necesidades alimentarias que cubrir-como el consumo mayoritario del vino-. Del mismo modo, la cerámica destinada a la preparación de alimentos no guarda ninguna relación con los recipientes utilizados en época almohade. 
Ahora bien, ¿cuáles son los criterios para establecer la cronología de este contexto cerámico? El límite cronológico inferior resulta complicado de fijar, puesto que los contextos materiales generados con la conquista aragonesa todavía permanecen sin aclararse. No obstante, se puede situar provisionalmente en torno a mediados del siglo XIII, teniendo en cuenta, por un lado, la rotunda ausencia en la plaza de la Judería de las producciones de finales del siglo XII y el primer tercio de siglo -tanto levantinas como del valle del Ebro-, que se están empezando a reconocer en el castillo de Albarracín (HERNÁNDEZ, 2010; HERNÁNDEZ y FRANCO, 2010). Por otro, el estudio ha dejado claro las similitudes con el horizonte de colonización del área valenciana y alicantina, fechado a partir de 1240-1250. Desde esta perspectiva, la vajilla de la plaza de la Judería se distingue claramente del repertorio consumido en Valencia durante la primera mitad de la centuria.

El límite superior lo constituye la total ausencia de la vajilla esmaltada y polícroma de producción turolense, cuya aparición en el castillo de Albarracín parece situarse a partir del asedio de 1284, y elaborada desde finales de la centuria.

El repertorio cerámico de la fase I de la plaza de la Judería permite ejemplificar el tipo de servicio utilizado a partir de mediados de la centuria, aproximadamente. Una vez que los productos andalusíes van desapareciendo del mercado debido al desmantelamiento de las manufacturas almohades, la sociedad feudal comienza a adquirir los recipientes elaborados por los nuevos centros productores, tal y como se observa en Barcelona a lo largo de la primera mitad del siglo XIII, en Teruel a partir de mediados de la centuria, y en Valencia poco después.

\section{Fase II (ca. 1285-1310)}

El complicado y variado panorama que caracteriza la cerámica durante la etapa anterior se va a modificar sustancialmente en la siguiente etapa, cuyos cambios se ven reflejados en la Fase II. Dentro del repertorio cerámico de cocina, solo se han obtenido ejemplares de la serie olla, conservados muy parcialmente.

-Olla II (Fig. 5. 12). Corresponde a un recipiente de cuello corto rematado por un borde grueso, ya presente en el período anterior, y que ha evolucionando hasta formar un pequeño labio horizontal. Contextos postconquista de la ciudad de Valencia contienen una olla semejante, probablemente elaborada en Paterna (MARTí et alii, 2007: p. 38, lam. 10, tipo 4-15).

-Olla III (Fig. 5. 13). Este modelo se caracteriza por un cuello muy corto, que apenas queda separado del cuerpo. Se ve acompañado por un borde muy engrosado de perfil rectangular, ligeramente desarrollado al interior, característica que identifica a esta producción. Ejemplares idénticos se han encontrado en la ciudad de Teruel en conjuntos fechados a partir de fines del siglo XIII, destacando el ejemplar procedente de la plaza de San Juan (ORTEGA, 2002: p. 124, Lam. XLIX, 1). Por otro lado, en las producciones de Paterna aparece una olla caracterizada por este borde engrosado rectangular, sin cuello diferenciado (MESQUIDA, 2009: p. 148, fig. 124, 2 a-d), habiendo sido identificada con uno de los recipientes posconquista en Valencia (MARTÍ et alii, 2007: fig. 10, 9). Las semejanzas entre las ollas turolenses y valencianas son claras, lo que demuestra que una similar vajilla fue elaborada desde ambos centros alfareros para abastecer a una sociedad semejante.

Para la mesa, si bien parece mantenerse en el mercado algunos de los recipientes previos como los jarros sin cubierta, la pieza mejor representada es la escudilla. Este recipiente de uso individual y destinado a servir los alimentos se va a llevar por delante toda la variada tipología de piezas que definían el horizonte anterior. Todas las piezas presentan la superficie interior vidriada, cubierta por un denso esmalte de color blanco y, a veces, acompañada por una decoración pintada en color verde y morado. La presencia de esta vajilla de elaboración local permite situarse cronológicamente a partir de finales del siglo XIII, dentro del contexto de la consolidación de la nueva producción manufacturera feudal. 
-Escudilla I (Fig. 5. 14). Este tipo de recipiente abierto, poco presente en el conjunto cerámico de la plaza de la Judería, ya ha sido constatado en la fase anterior, aunque con mayor tamaño (Fig. 4. 6). Sin embargo, el esmalte estannífero sustituye al barniz de tono verdoso. Se trata de un recipiente de perfil hemisférico, con un ligero quiebro de perfil en la parte inferior de la pieza. La composición decorativa está compuesta por un motivo central que ocupa el fondo de la pieza, formado por un triángulo inscrito a su vez dentro de un círculo, mientras que la pared se completa con una banda radial. Todos los motivos están pintados en manganeso, mientras que el verde se ha reservado para rellenar los trazados principales.

-Escudilla II (Fig. 5. 15). Corresponde al recipiente más numeroso dentro de este servicio de mesa. Se caracteriza por un pie anular y perfil carenado, generalmente remarcado por una fina moldura. El tercio superior de la pared es cilíndrico. Presentan un fino abombamiento en el desarrollo de la pared inferior, por debajo de la carena, que le aporta al perfil una ligera sinuosidad. Estas características también se dan en otras piezas turolenses de principios del siglo XIV y del castillo de Albarracín (ORTEGA, 2007b: no 286). Este modelado de la pieza se irá abandonando a lo largo de la primera mitad de la centuria, a favor de perfiles ligeramente cóncavos o rectos (ESCRICHE, ORTGA, 2002: no 29 y 54).

En el área levantina, este modelo está escasamente representado. La excepción procede del castillo de Lorca, con un ejemplar de escudilla sin cubierta vidriada y cuyo perfil es similar al tipo turolense (GALLARDO, 2010: p. 139, fig. 13-5.8). Según sus investigadores, pertenece a la fase de ocupación feudal de la alcazaba, ya en la segunda mitad del siglo XIII. Aunque esta pieza no está dotada del estilizado borde característico de las primeras escudillas decoradas turolenses -la pared finaliza en un fino borde apuntado-, en cambio muestra la carena ligeramente moldurada y el perfil sinuoso, al igual que los ejemplares de turolenses.

Si bien es posible que este recipiente tenga como antecedente algún modelo de la vajilla almohade, más bien parece derivar del plato I, muy abundante en la fase anterior. De este modo, este plato podría formar parte del proceso de transformación del ataifor almohade hacia la escudilla II, una muestra palpable de la innovación de los alfareros feudales. Similar consideración puede realizarse sobre la escudilla I, también presente a partir de mediados del siglo XIII. El conjunto de la vajilla de mesa durante estas dos etapas es el resultado de la transformación social feudal.

-Escudilla III (Fig. 5. 16-17). Este tipo de pieza presenta un aspecto muy característico: un pequeño recipiente abierto con perfil hemisférico muy abierto. El borde es sencillo, apuntado, aunque remarcado por dos gruesas acanaladuras. Los dos ejemplares estudiados muestran una composición decorativa muy interesante, basada en la misma estructura: motivo central dentro de un círculo situado en el fondo y banda concéntrica que ocupa el resto del campo decorativo. En los dos casos se desconoce el motivo central por el estado incompleto de las piezas. La banda está compuesta por una alternancia entre flores cordiformes dispuestas del revés y otro motivo, que varía según la pieza. El motivo de la flor cordiforme, surgido por la unión de dos palmetas es habitual tanto del repertorio turolense como del valenciano. El motivo vegetal alterna, según cada pieza, con una banda enladrillada dispuesta en oblicuo, o con microelementos de relleno a base de espirales complementados con trazos cortos y puntos, formando una pequeña composición triangular.

Este modelo ornamental, tanto en su organización como en sus motivos, parece formar parte del repertorio surgido de las primeras manufacturas esmaltadas de Teruel, tal y como queda representado en niveles fechados a finales del siglo XIII en el castillo y en la torre del Andador de Albarracín (ORTEGA, 2002: p. 124).

Durante esta fase, la cerámica culinaria sufre una reducción en su repertorio, aunque manteniendo las pautas anteriores, con una tendencia clara hacia el predominio de los recipientes con cuello corto y borde engrosa- 
do de perfil rectangular. En la fase posterior, la homogeneización será total, con el dominio de este tipo de olla.

La vajilla es sometida, en cambio, a una vital transformación. La aparición de unos recipientes cubiertos por un denso esmalte de color blanco lechoso, y decorados mediante unos motivos pintados en verde-morado, constituye la característica fundamental de este conjunto cerámico. La incorporación de este revolucionario tratamiento de las piezas se ve acompañado por la aparición de un nuevo recipiente, la escudilla carenada, que probablemente procede del ataifor carenado anteriormente consumido.

Una vez reconocido el servicio cerámico, es necesario situar cronológicamente este contexto material, en el cual ha quedado perfectamente fosilizado el proceso de radical transformación del repertorio turolense. Aunque, en el fondo, la cuestión se puede reducir a poder situar el inicio de las producciones esmaltadas en Teruel. El análisis comparativo de estos materiales se beneficia de los resultados obtenidos en el castillo de Albarracín, un conjunto estratificado de increíble interés. Según su periodización, la irrupción de la vajilla esmaltada -claramente de procedencia turolense- se sitúa en el entorno del asedio de 1284 (HERNÁNDEZ, 2010; HERNÁNDEZ y FRANCO, 2010). Esta circunstancia no permite retrasar, por lo tanto, más allá del último cuarto del siglo XIII el inicio de la producción esmaltada de Teruel, o, para ser más exactos, su irrupción en el mercado de Albarracín. Constituye también el límite cronológico inferior de la Fase II de la plaza de la Judería.

Por el otro lado, las cuidadosas composiciones decorativas de la vajilla esmaltada no permiten alejar el límite cronológico superior de este conjunto más allá de la primera década del siglo XIV.

De todos modos, el intento por establecer unas determinadas cronologías no debe tomarse como una cuestión maximalista, puesto que sostener una fecha, unos años antes o después, resulta de escaso interés a falta de cronologías absolutas. En cambio, lo más adecuado es poder determinar el proceso por el que se configuró esta nueva producción y su rápida aceptación por el mercado. En este asunto, la estratigrafía de la plaza de la Judería sirve para reconocer la aparición y evolución de la cerámica esmaltada dentro del proceso formación de la nueva vajilla feudal.

\section{Fase III (ca. 1315-1340)}

El repertorio destinado a la cocción de alimentos durante esta fase está formado por varios tipos de olla.

-Olla III (Fig. 6. 18). Corresponde a un recipiente de perfil globular, cuello corto y borde engrosado de perfil rectangular, de medias dimensiones. Este modelo aparece con o sin cubierta vidriada al interior. Sin ninguna duda, se trata del modelo mayoritario en esta etapa, aunque ya estaba presente desde fines del siglo XIII, como se ha visto con anterioridad. Es habitual encontrarlo en contextos arqueológicos de la ciudad de Teruel fechados a partir de principios del XIV (ESCRICHE, ORTEGA, 2002: Lam. XLIX, 4), convirtiéndose en el recipiente culinario mayoritario en los años centrales del siglo (ORTEGA, 2002: p. 127).

A pesar del dominio cuantitativo que ejerce la olla III, es necesario prestar atención a la aparición durante esta fase de un reducido grupo de ollas caracterizado por sus pastas de cocción reductora. Se trata en general de recipientes de mayor tamaño que los hasta ahora vistos. Si bien tienen un papel minoritario a tenor de su escasa representatividad, muestran una mayor variedad formal, puesto que se han identificado tres ejemplares distintos.

-Olla IV (Fig. 6. 19). En esta pieza el borde forma un amplio labio de perfil oblicuo, moldurado al exterior en forma de cornisa. No resulta forzado relacionar esta pieza con las ollas grises catalanas de "labio moldurado", $y$, en particular, con las procedentes del área de Tarragona, cuya de difusión interrumpe a partir de inicios del siglo XIV. Sin embargo, los paralelos más claros proceden del área levantina en contextos postconquista (MARTí et 

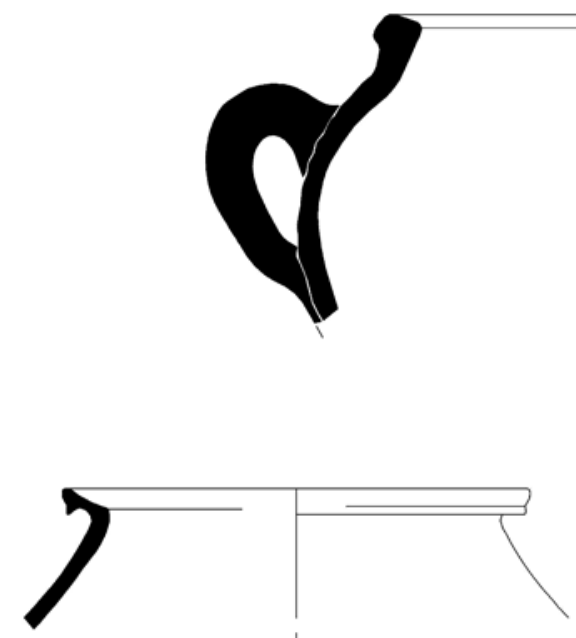

19
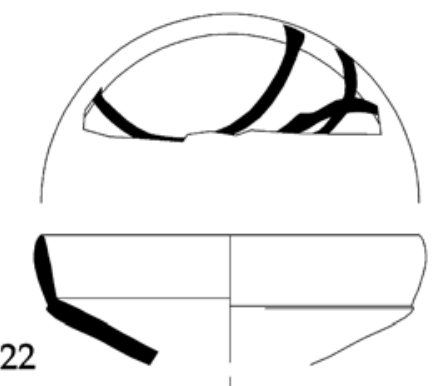

23
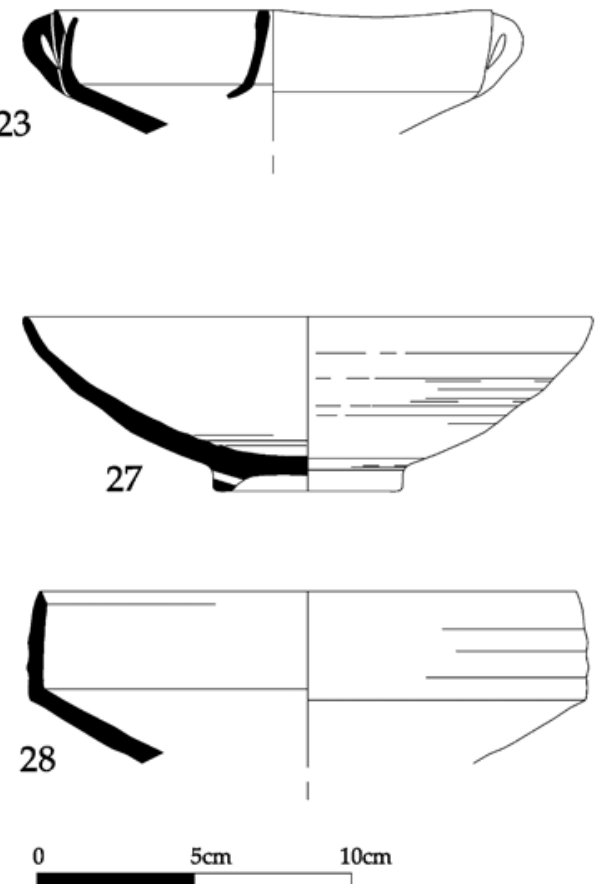
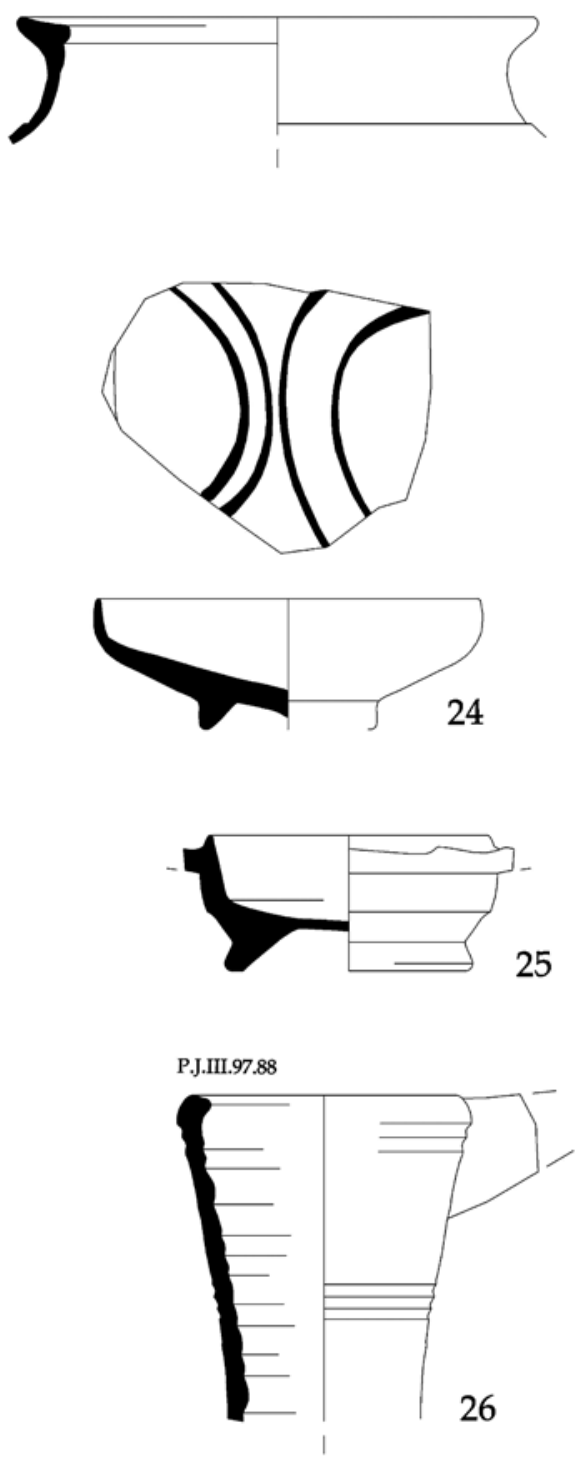

Figura 6. Repertorio cerámico de la plaza de la Judería de Teruel. Fase III: cocina y vajilla 
alii, 2007: pp. 38-39, lam. 10, 11-14). Dos ejemplares idénticos provienen del castillo de Uxó, fechados de manera genérica en los siglos XIII y XIV (BAZZANA et alii, 1988: p. 253, fig. 134: 259 y 1617). En la ciudad de Valencia aparecieron otros ejemplares de este tipo de olla (LOPEZ et alii, 1994: p.400-402, fig. 199-3, 200-3). Del Castell d'Ambra, en las proximidades de Denia, procede otro ejemplar todavía más remarcado fechado en la segunda mitad del siglo XIII (AZUAR et alii, 1999: p. 284, fig. 5). Con estos antecedentes, no parece descabellado plantear un probable origen castellonense para este tipo de ollas, como ha apuntado J. Martí, teniendo en cuenta su fuerte presencia en contextos de la colonización aragonesa.

-Olla V (Fig. 6. 20). Muestra un borde vuelto muy convexo que finaliza en un pequeño labio caído, ligeramente moldurado por una incisión central. La superficie exterior presenta bajo el borde varias marcadas acanaladuras. En la ciudad de Valencia aparece una olla gris semejante con un fino labio remarcado por una acanaladura para encajar la tapadera. (ROSSELLÓ, LERMA, 1999: p. 305, fig. 4). Los autores la identifican como producción claramente catalana por la presencia de desgrasante micaceo, en un contexto cronológico situado en torno a fines del siglo XIII.

La aparición de ollas reductoras en contextos cerámicos bajomedievales del sur de Aragón está bien documentado -aunque permanezca en gran medida inédita-, correspondiendo posiblemente a producciones foráneas procedentes del área catalana. Así, del castillo de Alcañíz procede un variado conjunto, el cual, sin embargo, apenas guarda ningún paralelismo con estos ejemplares. También se puede plantear dicha procedencia en el caso de ciertos ejemplares localizados en Teruel y caracterizados por un borde con cornisa moldurada, cuya producción se sitúa exclusivamente en el área leridana a partir del siglo XIII (ORTEGA, 2002: p. 125, lam. XLIX2). Sin embargo, no se corresponden con las piezas procedentes de la plaza de la Judería. A partir del segundo cuarto del siglo XIV la presencia de las ollas grises empieza a disminuir en la ciudad de Teruel, resultando testimonial a partir de mediados la centuria. Así parece ocurrir también en Valencia, tal y como queda atestiguado en el solar de Las Corts (LOPEZ et alii, 1994: p. 400) y en la plaza de la Almoina (PASCUAL et alii, 1987).

-Olla VI (Fig. 6. 21). El tercer tipo está formado por un recipiente con cuello cilíndrico corto, y borde exvasado formado por labio oblicuo, engrosado y ligeramente moldurado al interior mediante estrangulamiento. Presenta fina escotadura en el hombro. Está elaborado mediante cocción mixta, con un núcleo de color gris claro y las superficies de color rojizo claro. El paralelo más próximo corresponde a un tipo de olla cuya elaboración se viene situando en la ciudad de Zaragoza. Se caracteriza por cuello cilíndrico remarcado mediante escotadura en le hombro y un labio oblicuo, y durante los siglos XIII y XIV se distribuyó ampliamente por el valle del Ebro, alcanzando las tierras turolenses. Ejemplares de olla idénticos han sido hallados recientemente en contextos bien estratificados del casco urbano de Zaragoza, como el Paseo Independencia y el Teatro Fleta, fechados a partir de mediados del siglo XIII 8 (GUTIERREZ, 2010: pp. 445-447, fig. 10 y 19).

Otras muestras de esta producción de ollas han sido halladas en la Meseta occidental, como en la localidad de Ágreda, formando parte de contextos materiales fechados en la primera mitad del siglo XIII, durante la primera ocupación mudéjar de la morería9 (HERVÁS, RETUERCE, 1998: fig. 1; TURINA, 1998: p. 807).

8 Aparecen asociadas a escudillas carenadas y polilobuladas con asas, y a recipientes barnizados con decoración estampillada bajo cubierta, cerámica que viene siendo definida como "mudéjar" y cuyo centro productor se ubica en Zaragoza a partir de inicios del siglo XIII.

9 Se han recuperados dos tipos de este recipiente, uno con el borde moldurado al exterior y ligeramente recrecido al interior, y otro con un labio al exterior oblicuo, también ligeramente recrecido al interior. Se acompañan de ataifores carenados con cubierta barnizada al interior y círculos incisos. 
En resumen, el menaje destinado a la cocina está dominado por el tipo de olla III, al que se incorporan importaciones procedentes hipotéticamente del área catalana y zaragozana, aunque en un porcentaje muy reducido. Cabe destacar la inexistencia de recipientes con cuello acampanado, borde vuelto y labio redondeado, que se harán mayoritarios a partir de mediados del siglo XIV en las producciones turolenses, imitando a los modelos que se estaban elaborando en cerámica gris (ORTEGA, 2002).

La vajilla utilizada en la mesa está formada, casi en exclusiva, por producciones turolenses clásicas, pintadas en verde/manganeso bajo esmalte blanco. El grupo claramente mayoritario está formado por la escudilla, habiéndose diferenciado tres modalidades.

-Escudilla II (Fig. 6. 22, Lam. 4). Mayoritario resulta este recipiente caracterizado por la carena alta, al igual que ocurría en la fase anterior. Habitualmente muestra una carena remarcada por una fina moldura bajo la carena. Se trata de piezas de menor tamaño que en los ejemplares más antiguos, y está decorada mediante dos dobles trazos semicirculares en verde que se cortan.

-Escudilla IV (Fig. 6. 23, Lam. 4). A pesar de su exigua presencia en el conjunto material de la Judería, no se deben pasar por alto las piezas carenadas que presenta un perfil polilobulado en el tercio superior de la pared. Y esto se debe a que constituye uno de los recipientes más característicos de la producción alfarera turolense bajomedieval, muy bien representada en los contextos cerámicos de Teruel y Albarracín entre fines del siglo XIII e inicios del XIV (ORTEGA, 2007b: n 287-289) y Molina de Aragón. Algunos rasgos como los lóbulos poco marcados, una carena suave y un reducido tamaño, sitúan su cronología a partir de los inicios del siglo XIV, aunque su presencia será más numerosa desde mediados de siglo (ORTEGA, 2002: p. 126, lam. LIV).
La pieza se completa con dos pequeñas asas verticales, que se extienden entre el borde y la carena. Esta particularidad tan apenas ha sido documentada en las producciones turolenses. Sin embargo, se han localizado recipientes abiertos con doble asa en otros contextos arqueológicos bajomedievales en Aragón, como la plaza Santa Marta de Zaragoza, probablemente de elaboración local (AGUAROD, 1991) y el castillo de Novallas, próximo a la frontera con Castilla (BIENES y GARCÍA, 1989), aunque no estén contextualizados. Por otro lado, la escudilla con asas es habitual en la Meseta central, elaborada en los alfares de Ágreda (HERVÁs, 2001). También aparece en el área leridana, estando bien representada en contextos urbanos durante los siglos XIII-XIV, aunque los ejemplares documentados no muestran un perfil lobulado (LORIENTE, OLIVER, 1992: p.141).

Esta escudilla con asas, destinada seguramente al consumo de sopas y caldos, constituye otra de las muchas novedades suministradas por los diversos alfares a partir de finales del siglo XIII. El hecho de que diversas versiones del recipiente formen parte de contextos en el área castellana, aragonesa y leridana permite vincularlo con la vajilla utilizada en durante los siglos XI y XII en el ámbito feudal, sin paralelos en el área andalusí.

-Escudilla V (Fig. 6. 24, Lam. 4). Este variante de escudilla con carena redondeada, fue habitualmente elaborada por los alfares turolenses a partir de mediados del siglo XIV ${ }^{10}$. En general, se trata de piezas de menor tamaño que los precedentes.

Junto al dominio ejercido por la escudilla, la mesa se completa con una pieza de carácter minoritario, el salsero (Fig. 6. 25, Lam. 4). Se caracteriza por un receptáculo central con pie anular, paredes rectas y amplias alas horizontales. La decoración pintada se reduce a unos trazos en su interior. Se trata de una pieza muy

10 El Catálogo de Operiis terre turolii presenta un rico muestrario de este tipo de recipiente, sobre todo de piezas fechadas a partir de finales de la centuria, momento en el que acompañan de variadísimas composiciones decorativas esquematizadas (ESCRICHE, ORTEGA, 2002, n 115, 116, 117, 120 121, 122 entre otros). 


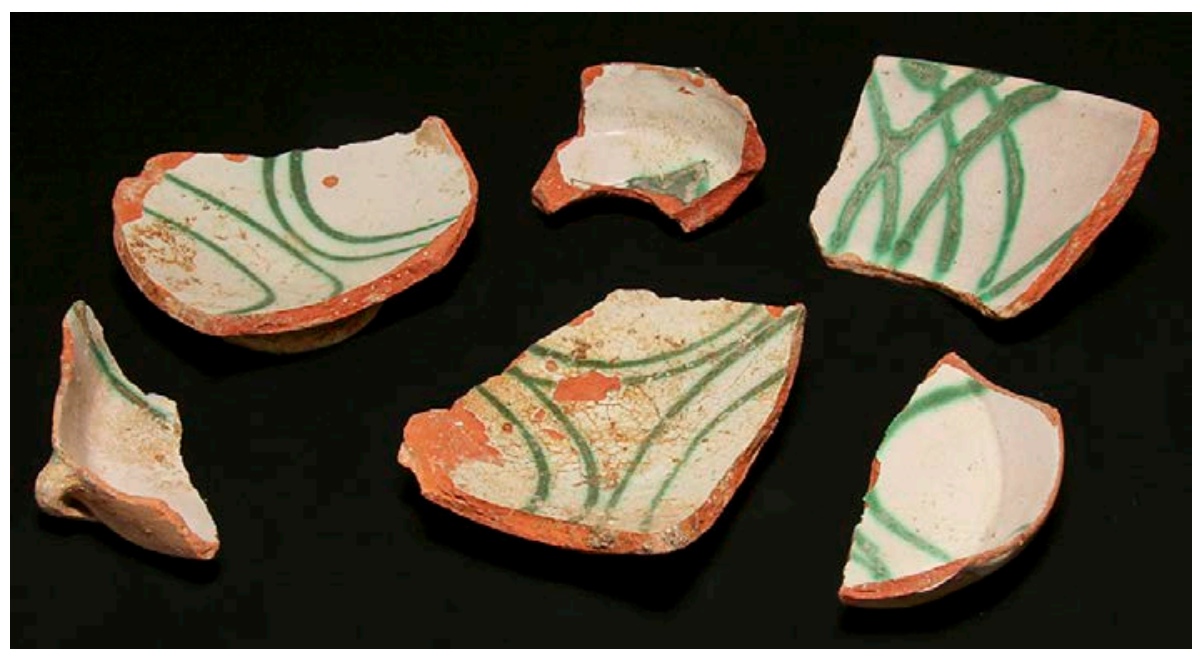

Lámina 4. Conjunto de vajilla, Fase III

elaborada por los alfares turolenses del siglo $X I V$, y frecuentemente exhibe una rica decoración pintada (ORTEGA, 2002: lam. LX).

En el caso del picher o pitxer (Fig. 6. 26), lamentablemente los ejemplares recuperados son muy fragmentarios e incompletos. Desde un punto de vista morfológico, pueden considerarse una evolución desde los primeros recipientes barnizados con decoración acanalada en el borde, hacia el prototipo clásico con borde reentrante. Este aspecto sitúa aproximadamente la cronología con anterioridad a mediados de siglo.

En lo que respecta a las composiciones pintadas, las cuidadas composiciones que caracterizan la primera producción decorada turolense-ejemplificadas en la fase II de la Judería- han empezado a evolucionar hacia modelos más sencillos, vinculados con la producción masiva de vajilla, tal y como ha sido puesto de manifiesto por J. Ortega, sin que resulte oportuno incidir más en esta cuestión (2002).

Además de la loza esmaltada, mayoritariamente en blanco, hay que señalar que la vajilla destinada a la mesa se completa con recipientes supervivientes desde la primera fase: con barniz y bizcochados. Sin embargo, la variedad formal que se daba anteriormente desaparece durante este período.
Por un lado, se observa la presencia numerosa del plato II (Fig. 6. 27, Lam. 5). Esta variante del recipiente muestra un perfil curvo muy abierto con borde simple redondeado, y la superficie interior cubierta por un barniz de color melado. Se acompaña de un doble círculo inciso en el fondo, como único motivo ornamental. Aunque se puede considerar a priori que procede del repertorio tardaandalusí, la vajilla de mesa almohade no cuenta con paralelos demasiado claros, como ocurre en el Castillo de Lorca (GALLARDO, 2008: p. 141, fig. 13-5.2). No obstante, la existencia de este tipo de recipiente de mesa está constatada en el repertorio turolense desde el último tercio del siglo XIII.

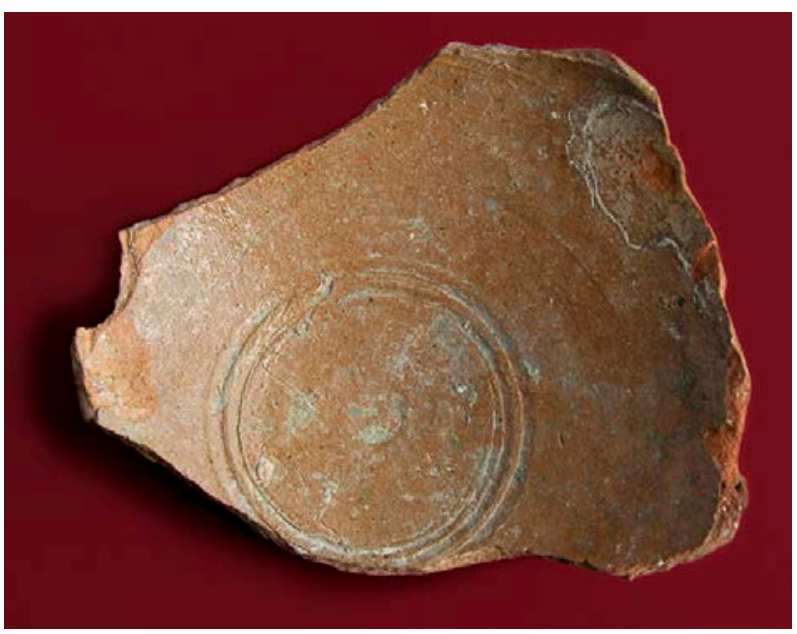

Lámina 5. Plato II, Fase III 
Por otro, se mantiene la presencia minoritaria de la altamía (Fig. 6. 28), un tipo de cuenco característico de la alfarería turolense que nunca fue dotado de cubierta vidriada. A diferencia de los ejemplares más antiguos, ahora muestra un perfil menos carenado.

Si en la etapa anterior ya se observa una reducción de la variedad formal en el repertorio de cocina, con una tendencia clara hacia el predominio de los recipientes con cuello corto y sencillo borde engrosado de perfil rectangular, a partir de esta etapa la homogeneización será casi total con el predominio de la olla tipo III. Esta circunstancia permite situarse cronológicamente en las décadas centrales de la primera mitad del siglo XIV, teniendo en cuenta que la variedad de los modelos en momentos precedentes prácticamente ha desaparecido. También cabe destacar la inexistencia de recipientes con cuello acampanado, borde vuelto y labio redondeado, que se harán mayoritarios a partir de mediados del siglo XIV en las producciones turolenses.

Es de destacar la presencia, aunque escasa, de ejemplares de ollas grises. Los escasos recipientes importados de pasta reductora de procedencia catalana, cuya presencia en los conjuntos turolenses se reduce progresivamente a lo largo del segundo tercio del siglo XIV, confirma aquellas fechas. Al respecto, resulta interesante recordar el conjunto cerámico recuperado en la torre del Andador de Albarracín, en el cual se da un predominio de ollas grises y escudillas polilobuladas en su fase II (ORTEGA, 2002). Esta asociación, similar a la recuperada en la fase III de la plaza de la Judería, puede situarse cronológicamente a partir de 1290, al menos.

La vajilla esmaltada responde, de manera genérica, al proceso de evolución formal detectado a partir del primer tercio del siglo XIV, en el que se empiezan a dar las primeras modificaciones del repertorio, especialmente decorativas, que se consolidan a lo largo de la segunda mitad de siglo. Como se ha comprobado, este conjunto cerámico es consecuencia directa de los cambios aportados por la evolución que trajo consigo la introducción de la vajilla esmaltada y decorada. De los recipientes surgidos en los precoces alfares a partir de mediados del siglo XIII ya no queda ningún rastro, salvo el eco.

Dentro de las formas abiertas, la escudilla carenada -mayoritaria en el período precedente- continúa siendo numerosa, aunque se ve acompañada por ejemplares de carena redondeada y piezas polilobuladas. En este último caso, hay que destacar que se trata de recipientes con los lóbulos poco marcados, un aspecto evolucionado que aleja su cronología de las primeras décadas de la centuria. A pesar de que este conjunto no ha proporcionado demasiados ejemplares, la presencia de la escudilla polilobulada está claramente atestiguada desde finales del siglo XIII, especialmente en Albarracín, como ya se ha indicado. La presencia del pícher, uno de los recipientes surgidos ex novo en los alfares feudales peninsulares, es otra evidencia de este progresivo cambio en el que los modelos surgidos de las primeras producciones feudales sin esmalte se están sustituyendo por otros nuevos, adaptados a las necesidades y gustos de la creciente sociedad.

Además, hay que señalar la enorme disminución, en el servicio de mesa, de la vajilla no vidriada, presente desde la etapa precoz. Si bien todavía aparece algún fragmento de jarro y tazita -seguramente de carácter testimonial-, la representación de piezas bizcochadas se reduce básicamente a la forma altamía. No hay duda de que el gran éxito de los productos vidriados arrinconó a los recipientes sin cubierta a un papel minoritario. Algo parecido ocurrió con la vajilla destinada a la cocina, en la cual la presencia de un barniz transparente es muy destacada.

El conjunto cerámico formado al final de la Fase III es un testimonio perfecto de la vajilla usada durante los años centrales de la primera mitad del siglo XIV. Para situar el límite cronológico inferior tenemos en cuenta la desaparición de las primeras producciones en cerámica esmaltada, y que sin duda caracterizan el horizonte material precedente: 
cuidadosas decoraciones pintadas en morado. El límite superior viene determinado por la ausencia de ciertos recipientes mayoritarios, como tajadores, pícheres y ollas de borde vuelto, y cuya aparición se sitúa a partir de mediados de la centuria, en los inicios de la estandarización productiva desarrollada por los alfares turolenses. A partir del segundo cuarto del siglo XIV, se observan las primeras transformaciones de los conjuntos cerámicos que habían caracterizado a la primera vajilla esmaltada (ORTEGA, 2002: p. 127). Sin embargo, esta tendencia y su evolución ya han sido adecuadamente estudiados, o, en su defecto, deberán ser analizados en otro momento y sobre la base de otros registros.

\section{La difusión de la nueva cerámica feudal}

El itinerario efectuado a lo largo de estas páginas ha intentado identificar algunos aspectos de la evolución social de una determinada vajilla en un preciso período: el desarrollo de la villa de Teruel ocurrido entre mediados de los siglos XIII y XIV. De todas maneras, la importancia del conjunto material procedente de su plaza de la Judería resulta meridiana, más allá de los resultados del estudio. La ausencia de contextos materiales coetáneos que hayan sido publicados, convierte a este conjunto en un instrumento adecuado para reconocer la dinámica seguida en la transformación de las estructuras sociales, demandantes, en definitiva, de dichos productos. Esto implica avanzar más allá de las piezas que vienen siendo consideradas representativas de cada fase o contexto. Por ello, este repertorio va a permitir situar con más precisión los materiales procedentes de conjuntos clásicos, no bien estratificados, como los procedentes de la plaza de S. Juan. Y, del mismo modo, resultará imprescindible relacionar estos contextos con los recientes hallazgos de los conjuntos alfareros turolenses de La Nevera (IBAÑEZ, 2010) y Bajo Los Arcos (RODRIGUEZ, 2010).
La revisión de los materiales más antiguos procedentes de aquella mítica plaza turolense no deja excesivo margen de duda: la vajilla almohade ya ha desaparecido por completo del conjunto cerámico, y no existe rastro de los recipientes feudales de tradición más septentrional. Del análisis de la primera etapa en la plaza de la judería de Teruel se reconoce claramente una gran semejanza con el repertorio postconquista que está siendo identificado en el Levante, fechados los dos a partir de mediados del siglo XIII (MARTí et alii, 2007; TORRÓ, 2003). Esto, a su vez, permite diferenciar a ambos de los contextos precedentes, los almohades del primer tercio del siglo ${ }^{11}$. La total ausencia de los característicos productos andalusíes elaborados durante la primera mitad de la centuria es consecuencia de varios aspectos sociales derivados de la conquista feudal del Levante: que estos centros productores ya han dejado de funcionar, que las redes comerciales se han desmantelado y que la población consumidora ya no los demanda.

Ahora bien, su rastro, o, mejor dicho, su influjo, son también detectables en algunos aspectos del repertorio estudiado, exclusivamente durante su primera etapa. Así se ha reconocido en algunos de los recipientes, que derivan formalmente de los modelos almohades, aunque claramente transformados. Este comportamiento híbrido ha sido comprobado en otras áreas del entorno del Mediterráneo occidental (MARTíy PASCUAL, 1998). De este modo, la nueva vajilla surgida a lo largo del siglo XIII de las primeras manufacturas feudales del área barcelonesa, leridana, valenciana y turolense derivaría de la parcial transformación de las producciones precedentes, tanto en el repertorio como en los aspectos técnicos. Y, lo que es más importante, sería el resultado de una brutal adaptación de una mano de obra, de unos recipientes, de unos conocimientos técnicos existentes a las condiciones y posibilidades creadas por la nueva industria y a los gustos del consumidor. Quizás una de las razones de mayor peso a la hora de entender

11 En este sentido, el conjunto material del castillo de Albarracín fechado en los dos primeros tercios de la centuria va contribuir de manera decisiva a vislumbrar los radicales cambios que supuso la conquista feudal aragonesa. 
esta influencia se puede deber a la utilización de la mano de obra alfarera mudéjar, que ha quedado ahora desarticulada y sometida al nuevo régimen feudal. Así, apartada de los medios de producción que hasta entonces manejaba, irá siendo asimilada por los nuevos e instalada en los alfares que surjan. Otra de las razones tiene que ver con la propia demanda, puesto que una parte de los consumidores estarían acostumbrados a abastecerse de los centros alfareros levantinos, y en consecuencia, habituados a cierta vajilla.

En este sentido, se puede considerar este repertorio como el resultado de un profundo cambio social, por lo que cualquier aproximación teórica debe realizarse dentro de la problemática del surgimiento de la vajilla feudal peninsular y occidental. La cerámica destinada a la cocción de alimentos no guarda ninguna relación con los modelos precedentes levantinos, prueba del cambio en las pautas alimentarias y culinarias. En el caso de la vajilla, los recipientes responden a una radical adaptación de una parte del repertorio elaborado con anterioridad en vistas a los nuevos usos sociales. Es significativa la eliminación de la hasta hacía poco tiempo exitosa y abundante vajilla para el servicio de líquidos, con jarritas, tinajas y jarras vertedoras. Aquella es sustituida por unos hasta entonces desconocidos jarros y tazas de una sola asa.

La reconstrucción histórica de los llamados períodos de transición siempre ha resultado muy confusa, no queda claro si debido a la dificultad de los propios procesos o a la complejidad de su percepción e identificación por parte de los historiadores. En el caso de la transición de la sociedad andalusí a la feudal del ámbito mediterráneo durante los siglos XII y XIII, que dará lugar a la estructura política de la Corona de Aragón, se podría definir como un largo período de rápida ruptura, en el cual la sustitución de las estructuras sociales necesitó de cierto tiempo. Desde el punto de vista de la cultura material, se viene reconociendo una etapa de complicada delimitación en la cual fluctúan pervivencias e innovaciones, como en el área urbana de Valencia (CoLl et alii, 1988; TORRÓ, 2003).
Uno de los planteamientos más repetidos en la investigación y divulgación es el continuismo que se viene reconociendo entre la alfarería andalusí y feudal, fundamentalmente en el caso de la loza decorada y esmaltada, aunque se puede extrapolar a otras manifestaciones artísticas o productivas. Esta postura se basaba en dos aspectos: la permanencia física de la población andalusí, y la continuidad tecnológica en mano de los alfareros andalusíes. La combinación de ambas da como resultado la permanencia cultural rastreable en la cerámica. Sin embargo, el análisis desprejuiciado de los datos, documentales y materiales, indica todo lo contrario: la conquista feudal supuso el punto de partida de un traumático proceso de ruptura de las estructuras social, de poblamiento y productiva existentes, como ha puesto de manifiesto J. Ortega (2002). Y esta nueva percepción se ve reflejada, por ejemplo, en las habituales prácticas de emigración, traslado forzoso y esclavización a las que fue sometida la población local musulmana. Las fuentes documentales ponen de manifiesto la ausencia de aljamas en la Extremadura aragonesa. En este caso, resulta muy representativo el caso de Teruel, villa sobre la cual la Corona tuvo especial empeño por apoyar la creación de una morería en 1285, impulsando la llegada de musulmanes foráneos a partir de moros redimidos de la esclavitud y de inmigrantes (ORTEGA, 2002: pp. 54-55). Desde la propia perspectiva tradicionalista, sin una continuidad de los moros tampoco se puede sostener la persistencia productiva. Este panorama ha quedado demostrado también en el territorio valenciano (MARTí, PASCUAL, 1999).

Las variables identificadas en este análisis de la cultura material no permiten seguir manteniendo que el desarrollo feudal a partir del siglo XIII fue resultado de una simple combinación entre cambio y continuidad, aunque estos conceptos puedan reconocerse aisladamente. Al contrario, es el cambio social el que explica que los habitantes del barrio de la judería de Teruel -fueran judíos o no- adquieran esos recipientes, puesto que los aspectos y rasgos de filiación andalusí que puedan percibirse son únicamente resultado de la adaptación y reinterpretación, bajo el 
amparo de una nueva industria alfarera para un nuevo mercado. No se debería insistir en exceso en estos influjos, puesto que su permanencia depende solamente de su acomodo con el modo de producción feudal. En este perspectiva, resulta absurdo seguir reconociendo una línea de continuidad entre la vajilla en verde/morado de los siglos Xy XI de surgida de talleres como Albarracín y Valencia, con la vajilla en verde/morado de los siglos XIIIXIV de Teruel y Valencia, puesto que ambas producciones responden a sociedades muy diferentes y son consecuencia de entidades sociales bien alejadas.

Sin embargo, esta situación no invalida ni entra en contradicción con la existencia de influencias, tanto morfológicas como decorativas. De este último caso, es la producción valenciana en reflejo dorado-azul, dentro de la loza decorada feudal, la que muestra con mayor claridad este influjo islámico, especialmente en sus primeras producciones. No obstante, esto se debe a la imitación que se llevó a cabo por parte de los alfares valencianos de los sistemas y motivos decorativos de la vajilla en dorado protonazarí (GARCíA, 2003), siendo ambas producciones coetáneas.

A lo largo de todo el siglo XIII, la mitad septentrional del Mediterráneo occidental fue escenario de la radical transformación de su vajilla cerámica. Este proceso se desarrolló en paralelo a la desaparición de una gran parte de la producción tardoandalusí en la Península Ibérica como consecuencia de la expansión de los reinos feudales. Desde el centro-norte de Italia, pasando por el sur de Francia y el área barcelonesa, hasta alcanzar el área turolense y valenciana, se va a ir extendiendo el uso de una nueva vajilla bastante homogénea tanto en recipientes como en recursos decorativos (MARTÍ, PASCUAL, 1999).

El final de la conquista de Valencia en 1245 y la toma de Albarracín en 1284 constituyen dos hitos cronológicos en la expansión feudal aragonesa. Y si bien resulta totalmente erróneo empeñarse en buscar su reflejo directo en las estratigrafías arqueológicas, no por ello dejan de ser útiles a la hora de manifestar las inflexiones de aquel proceso de producción social. Se puede decir que todo comenzó a cambiar con la conquista del reino almohade de Valencia (GUINOT, 2009). La incorporación de enormes territorios, recursos y población, pero sobre todo de una privilegiada salida al mar, van a provocar a lo largo de la segunda mitad de la centuria un considerable crecimiento demográfico y económico, así como una importante transformación social (ORTEGA, 2007a: p. 91). En este contexto resulta revelador que la villa de Teruel, avanzadilla aragonesa en su control del Levante desde el último cuarto del siglo XII, sea capaz de lanzar al mercado una nueva oferta alfarera con un ligero adelanto temporal sobre los centros valencianos. Y, además, que aquella vajilla sea ampliamente demandada. Esta circunstancia no debe de extrañar si se tiene en cuenta, por un lado, su condición de principal núcleo urbano -y, por ello, manufacturero- de un extenso territorio. $Y$ asumiendo, por otro, el enorme mercado potencial que se abrió en torno a sus principales ejes de comunicación: Jiloca/Jalón/Huerva hacia el N y Turia hacia el S. La extensión de las relaciones sociales y de los influjos culturales feudales, propiciarán el incremento de esta nueva demanda.

La evolución de la vajilla que se observa en el repertorio de la plaza de la Judería turolense, tiene un gran paralelismo con lo identificado en los contextos postconquista levantinos (MARTí et alii, 2007). Si bien éstos no forman un conjunto homogéneo, puesto que proceden de ámbitos urbanos -Valencia, Castellón-, fortificados - castillo de Ambra y Río (Alicante)-, rurales -Santa Fé de Oliva-, sí que responden, junto con el turolense, al nuevo modo de producción. Se dieron las condiciones productivas y de demanda para que unos novedosos recipientes fueran consumidos. No se trata tanto de un movimiento casuístico, de un encuentro paradójico entre dos fuerzas, como de la adaptación de unas fuerzas productivas por parte de los nuevos señores con el fin de cubrir una demanda. Serán las nuevas estructuras feudales las que propicien el desarrollo de una nueva industria destinada a abastecer a una población eufórica, los colonizadores. Y para ello no dudaron 
en aprovecharse de las antiguas fuerzas productivas andalusíes -alfareros desubicados, desorganizados y desplazados-, adaptando la vajilla que saben hacer a la nueva cadena operatoria y al nuevo mercado. La cuestión ha sido recientemente planteada por J. Martí y J. Pascual como una etapa que se mueve entre la pervivencia desorganizada de un saber hacer ... y ... las demandas del nuevo consumidor cristiano. Una etapa que se mueve entre el "know how" y el mercado (2007, p. 45-49). La comercialización proporciona mayor capacidad de inversión, y a su vez estimula una mayor producción. Éstos, a su vez, conducen a una simplificación del proceso productivo -repertorio más uniforme, sencillo, barato de elaborar-que compense el progresivo aumento de la demanda. En definitiva, la cultura material estudiada es un fiel reflejo del considerable crecimiento experimentado por la producción feudal en el SE de Aragón, factor determinante para que el incremento de las rentas feudales a extraer consolide a los propios señores. A su vez, este proceso va a propiciar la expansión de los mercados, el incremento demográfico y el desarrollo constructivo, como ha quedado bien reflejado en la ciudad de Albarracín para este mismo período (ORTEGA, 2007a: p. 86).

Construir un discurso acerca de los feudales y sus bienes de consumo no implica hablar solamente de la loza dorada valenciana o de las importaciones de mayólica. Los materiales estudiados permiten reconocer un panorama más variado y complejo. El impulso expansionista de los feudales propició que un amplio segmento del mercado quedara abastecido rápidamente desde dos centros alfareros principalmente, Teruel y Paterna/Manises. Tras una primera y fundamental fase "precoz", los dos núcleos manufactureros estaban preparados para asegurarse un consumo más o menos masivo lanzando la loza decorada y esmaltada. Es significativo que ambos centros productores compartieron similar repertorio formal y decorativo. Se puede afirmar que entre ellos se repartieron el negocio, con una ligera preponderancia del primero si se atiende a su anticipación y potencia inicial. Sin embargo, esta ventaja quedaría pronto superada con creces por el gran centro alfarero valenciano de Paterna-Manises (LOPEZ, 1984; MESQUIDA, 2004), especialmente debido a una mayor demanda y, sobre todo, al impulso que supuso lanzar al mercado la vajilla de reflejo dorado, cuyo éxito fue tal que modificó el mercado en la Corona de Aragón y en el Mediterráneo occidental, gracias al comercio marítimo.

\section{TERUEL COMO DEMANDANTE}

El panorama, que el repertorio cerámico de la judería de Teruel permite observar, es, simplemente, un reflejo del menaje comercializado en la ciudad, a pesar de que tenga un carácter parcial -por la propia intervención arqueológica, el proceso estratigráfico o la población que ocupó esta porción del núcleo urbano ${ }^{12}$.

Si se tienen en cuenta los aspectos técnicos -como cocción, pasta, modelado, barnices, tratamiento de la superficie y decoración-, se puede considerar que prácticamente toda la cerámica analizada presenta idénticas características. Si bien se reserva para otro momento el estudio de este conjunto realizado desde el lado de la producción, resulta necesario indicar que son los alfares turolenses los que dominaron el mercado de manera casi exclusiva, tanto para cocina como mesa. A tenor de estos resultados, es indiscutible que el mercado turolense fue abastecido mayoritariamente por los alfares locales desde mediados del siglo XIII. Además, resulta importante destacar que este origen local afecta a la totalidad de la cerámica usada durante la primera etapa ocupacional de la plaza, lo que viene a demostrar la considerable capacidad técnica y produc-

12 Si bien la población de la ciudad estaba formada por una mayoría de cristianos y dos grupos minoritarios, judíos y musulmanes, hemos obviado conscientemente de este estudio cualquier referencia a la influencia que las particularidades religiosas y alimentarias de aquellas comunidades pudieron tener en la configuración de las vajillas de cada vivienda. Esta decisión se basa en los escasos indicios materiales que permitan vincular determinado conjunto arqueológico con una determinada adscripción religiosa. 
tiva que ha alcanzado su industria alfarera en su etapa precoz. Este poderío durante la segunda mitad de la centuria, por otro lado nada extraño si se tiene en cuenta que coinciden centro productor y consumidor, se va a mantener claramente, aunque con algunos matices, a lo largo de las décadas siguientes. También resulta representativo el hecho de que la ciudad de Albarracín, ya a finales del siglo XIII, se abasteciera para la vajilla de mesa únicamente desde los alfares turolenses (HERNÁNDEZ, 2010; ORTEGA, 2007a: p. 94-95).

Sin embargo, al predominio casi absoluto de los productos locales hay que incorporar la llegada de recipientes de otras procedencias en la primera mitad del siglo XIV, aspecto de gran interés debido a su variedad: diversidad de centros -área zaragozana y catalana-, en períodos distintos, con productos diferentes. Aunque la presencia minoritaria de aquellas importaciones estaba ya comprobado, su localización en un conjunto estratificado aporta nuevas perspectivas. Por lo demás, no se puede descartar que estudios de mayor envergadura o con diferente enfoque reconozcan otras evidencias.

Si se siguiera la trayectoria de la expansión feudal aragonesa -comenzando en Zaragoza y descendiendo por el curso del Huerva y JalónJiloca hasta alcanzar Teruel, y proseguir por el Turia hasta Valencia-, es fácil reconocer una de las principales rutas de la colonización de la Extremadura aragonesa y el Levante. A pesar de no haberse llevado a cabo todavía ningún estudio de consideración, parece definirse como una de las principales vías de introducción de bienes de consumo a estos territorios. Los contextos arqueológicos manifiestan una presencia de producciones del área zaragozana, especialmente de ollas, a lo largo de todo el siglo XIII. Este comportamiento está siendo reconocido en el castillo de Albarracín, donde se observa una considerable proporción de estos recipientes en los niveles asociados con la reocupación feudal de la vieja alcazaba, desde inicios del siglo XIII ${ }^{13}$, para desaparecer a mediados del siglo XIV. Similar comportamiento se observa en la plaza de la Judería, al formar parte del repertorio de la fase III. Su localización indica que, durante este horizonte cronológico, todavía llegaron a difundirse los exitosos recipientes zaragozanos, aunque ya de forma testimonial.

Ahora bien, si se compara la exigua presencia de estas ollas en la plaza de la Judería con lo que ocurre en el castillo de Albarracín-donde se da una mayor y más dilatada difusión de estos productos- o en localidades de la Meseta como Ágreda, se puede pensar que su distribución resultó muy limitada en el mercado turolense.

Otra de las rutas de penetración y expansión feudal comienza en el territorio catalán. La presencia de importaciones de ollas grises de probable procedencia catalana está atestiguada en Aragón a lo largo del siglo XIII. En el castillo de Albarracín ha sido constatada a partir del último cuarto de la centuria. No obstante, no parece que dejara mucha huella en el consumidor, puesto que los centros alfareros locales ni se molestaron en imitar sus característicos recipientes. En este caso, se trata exclusivamente de ollas, y su representación es inferior al $5 \%$ respecto del volumen total de la vajilla culinaria perteneciente a la fase III.

Sin embargo, hay que destacar que dentro de la vajilla importada que llegó a Teruel, y en particular a la Judería, siguen sin identificarse los productos valencianos que pudieron llegar. Eso ocurre, al menos, con la vajilla de mesa decorada en verde y morado, cuya semejanza formal y estilística con las cerámicas turolenses complica su identificación. Ahora bien, la fortaleza de la producción local desde mediados del siglo XIII, reconocible en este conjunto cerámico, puede ser una de las razones para comprender la ínfima presencia de los productos valencianos. Es probable que la potencia de la nueva vajilla ofertada desde

13 En el caso concreto del tipo de olla con amplio labio oblicuo, su llegada a la vajilla del castillo de Albarracín se puede datar a partir del último tercio del siglo XIII, en el que viene a sustituir a otros modelos culinarios hasta ahora distribuidos. 
los talleres locales asegurara su hegemonía en el mercado del SO de Aragón, especialmente tras de la aparición de los recipientes esmaltados. Durante los siglos XIV y XV, la cerámica esmaltada de Teruel alcanzó una considerable comercialización, alcanzando desde el área urbana de Valencia por el SE, hasta el extremo oriental del reino de Castilla y gran parte de Aragón.

En cambio, la detección de la vajilla esmaltada en dorado y azul de origen valenciano no tiene dificultades, aunque parecen existir pequeños indicios que apuntan hacia una producción local de loza dorada, la cual no llegó a cuajar. Los escasos testimonios materiales permiten pensar que durante el segundo cuarto del siglo XIV pudieron llegar las primeras importaciones levantinas en dorado, aunque de manera muy exigua (ESCRICHE, ORTEGA, 2002: fig. 89-90; ORTEGA, 2007a: p. 94). Así se observa en el castillo de Albarracín, estando presente por primera vez una pieza perteneciente al estilo malagueño antiguo, en un nivel fechado a partir del segundo tercio del s. XIV. Parece que no será hasta el último tercio de la centuria - después de la guerra con Castilla- cuando este exiguo circuito comercial se consolide definitivamente, tal y como lo ejemplifica el magnífico conjunto cerámico recuperado en Fortanete, fechado entre 1390 y 1420 (ORTEGA, 2002: pp. 77-78, Lam. XXIX). En el conjunto de la plaza de la Judería la presencia de esta vajilla decorada es muy testimonial y está formada por importaciones valencianas en azul, a partir de inicios del siglo XV.

Así, la estructura del mercado turolense entre mediados de los siglos XIII y XIV estuvo dominada por las manufacturas locales, tanto para el servicio culinario como de mesa. Esta situación demuestra claramente que estos alfareros respondieron rápida y eficazmente a las demandas de la sociedad local, desde la etapa inicial de su producción. Aunque también se puede realizar una lectura inversa, reconociendo la importante respuesta dada por la demanda acerca de la vajilla ofertada por la industria alfarera local emergente, en un contexto de expansión económica y demográ- fica. Los principales aspectos que definen la evolución de la vajilla y que se reconoce en los recipientes estudiados -la particular y selectiva adaptación de los prototipos almohades, la introducción de la cubierta esmaltada, la desaparición/incorporación de recipientes, la selección de unos motivos decorativos concretos, etc.- son el mejor testimonio de aquel escenario. Únicamente durante la primera mitad del siglo XIV se observa la presencia de importaciones zaragozanas y catalanas, exclusivamente en vajilla de cocina y siempre de carácter minoritario. La exigua llegada de manufacturas foráneas puede manifestar la debilidad de las estructuras comerciales a la hora de introducir otros productos de consumo mayoritario en este territorio, sobre todo a medida que la vajilla de Teruel va extendiendo su área de distribución.

Respecto a las pautas seguidas por los turolenses a la hora de adquirir estos bienes de consumo, se observa una constancia a lo largo del período estudiado, a pesar de las modificaciones llevadas cabo en el repertorio formal. Sin embargo, es necesario apuntar que de los tres grandes grupos funcionales de cerámica, el que peor está representado en este conjunto corresponde a los contenedores de almacenamiento y transporte. Y, sin embargo, las gerres y alcolles destinados a contener agua, vino, aceite, harina o legumbres son los recipientes cerámicos más antiguamente recogidos en los protocolos notariales, como en Valencia (LOPEZ y COLL, 2006: p. 44).

En la cocina se utilizaron fundamentalmente ollas de medio tamaño y aspecto pesado, con una clara evolución de la demanda hacia recipientes más voluminosos y con amplia boca (Fig. 6. 18). La selección de recipientes no parece corresponder a ninguna variación en la dieta. Sin embargo, la presencia testimonial de la cazuela, como el significativo ejemplar de imitación levantina (Fig. 4. 3), pone de manifiesto cambios en los hábitos alimentarios durante la primera etapa, puesto que este recipiente -dotado de una prominente tapadera- está destinado a elaborar determinados guisos enraizados en la cultura islámica. 
Para el servicio de alimentos, el patrón de consumo está formado por un tipo de recipiente abierto de tamaño medio destinado a la presentación en la mesa, acompañado de varios de menor tamaño de uso individual, reservados para el consumo de caldos y guisos. A pesar de las diferencias formales observadas en estas piezas a lo largo de las tres etapas, no parecen corresponderse con ninguna variable gastronómica. En todo caso, es indudable la predilección por utilizar en la mesa recipientes de carácter personal, demostrando interés por las piezas de menor tamaño.

Aquella tónica es todavía más marcada en el servicio de bebida, el cual está dominado por recipientes de una sola asa, como el jarro y taza (Fig. 4.10 y 11), destinados probablemente al consumo de agua y vino. El testimonio es especialmente significativo en la primera etapa, con varios ejemplares completos de cada tipo. Sin embargo, parece observarse una evolución en los gustos del consumidor hacia piezas sin asa que se ven acompañadas por jarros vertedores de mayor tamaño (Fig. 6. 26), muy característicos durante el siglo XIV. La desaparición de recipientes individuales para líquidos en este conjunto a partir de la tercera etapa puede deberse a su sustitución por otras piezas.

Ahora bien, tampoco hay que perder de vista que no todo el menaje doméstico utilizado para uso alimentario se elaboraba en cerámica, puesto que se acompañaba de recipientes elaborados en otros materiales como metal, madera y vidrio, de los cuales no tenemos constancia material en este conjunto. Utilizando los datos proporcionados por los inventarios testamentarios de Valencia, se observa en la vajilla un dominio mayoritario de los recipientes de madera desde 1285 hasta finales del siglo XIV, cuando se equipara con el repertorio cerámico, el cual solamente es mayoritario desde mediados del siglo XV. En todo caso, el porcentaje que representan las piezas decoradas se sitúa en un $10 \%$ de media para los dos siglos. En la cocina, en cambio, las piezas de metal se mantuvieron mayoritarias hasta finales del siglo XIV, cuando la cerámica pasa a ser el material predominante para el fuego, alcanzando un $80 \%$ a finales del siglo XV (LOPEZ, 2002; LOPEZ y COLL, 2006: pp. 45-55). Considerando este comportamiento, se puede decir que la participación de los recipientes cerámicos dentro del menaje doméstico en la sociedad bajomedieval en 1250-1350 no es mayoritaria ni de lejos, aspecto a tener en cuenta al pensar en las pautas de consumo.

Desde un punto de vista social, se puede descartar la presencia de grupos sociales privilegiados en la plaza de la Judería, puesto que éstos eran consumidores de vajilla de metal - plata y bronce-, vidrio y de lozas importadas de prestigio, las cuales brillan por su ausencia en este conjunto. Sin embargo, intentar reconocer en detalle los mecanismos de consumo resulta complicado, a falta de otros conjuntos materiales o inventarios documentales próximos que puedan ser comparados. De todas maneras, el repertorio estudiado -caracterizado por su homogeneidad formal, decorativa y productiva- indica que sus consumidores, si bien no contaban con importaciones en sus mesas, tuvieron acceso a todo el catálogo de cerámicas locales. Es más. La generosa presencia de recipientes barnizados durante la primera etapa, y, especialmente, de piezas esmaltadas cuidadosamente decoradas durante la segunda etapa puede indicar que la población que los consumió fue, al menos, afortunada, puesto que dicha vajilla debía de corresponder al segmento más costoso dentro de la producción alfarera.

\section{CONCLUSIÓN}

El conjunto material mueble recuperado en 2004 bajo la plaza de la Judería de Teruel, constituye un reflejo directo de la demanda, es decir, de la sociedad que gustó, adquirió, usó y desechó la vajilla recuperada arqueológicamente. Los productos que se distribuían y consumían en la Extremadura aragonesa a inicios del siglo XIII poco tienen que ver con el repertorio utilizado unas décadas después. Es a partir de mediados de siglo cuando comienza a irrumpir una nueva vaji- 
Ila en una sociedad que se encontraba en pleno proceso de crecimiento económico. Sobre la base del tejido productivo previo pero sometido y adaptado por las nuevas relaciones feudales, surge una industria y un repertorio. De esta manera, y como ya se ha sido apuntado en otros trabajos, la aparición de la cerámica esmaltada debe entenderse como una etapa más dentro del proceso evolutivo de la nueva vajilla. Los aspectos que caracterizan la primera loza esmaltada, tanto formas como recursos decorativos, son una consecuencia del proceso realizado con anterioridad, donde se observan recipientes barnizados y bizcochados sin decoración. Esta tendencia de continua innovación se va a mantener e incrementar a lo largo de las décadas posteriores.

La documentación arqueológica realizada en el subsuelo de la plaza aporta nuevos datos para reconocer la implicación de la evolución de la vajilla dentro del proceso social feudal. Sobre todo porque son los contextos cerrados bien estratificados las herramientas más eficaces para demostrar con fiabilidad la producción social de la realidad, los mecanismos que vinculan las demandas del consumidor con el mercado y los productores. El lote cerámico es un simple registro histórico, pero no uno más entre muchos, puesto que la cultura material constituye un privilegiado y adecuado testimonio de unas determinadas relaciones de producción, las cuales constituyen el elemento configurador de la historia.

\section{AGRADECIMIENTOS}

Agradecemos a Rafael Azuar, Javier Martí, y, sobre todo, a Julián Ortega, sus comentarios y sugerencias que han permitido mejorar este artículo, aunque los posibles errores y deficiencias solamente son atribuibles al autor. Igualmente quiero señalar la buena acogida demostrada, en aquel momento, por los técnicos y responsables de la Dirección General de Patrimonio Cultural del Gobierno de Aragón a la hora de apoyar este estudio (HERNÁNDEZ, 2010).

\section{BIBLIOGRAFÍA}

AGUAROD OTAL, C. y ESCUDERO, F. (1991): Arqueología de Zaragoza: 100 imágenes representativas, Zaragoza.

ATRIÁN JORDÁN, P. (1979): "Informes de las excavaciones realizadas en la Plaza de la Judería", Teruel, 53, Teruel, pp. 44-46.

ATRIÁN JORDÁN, P. (1981): "Lámparas de Hanukkah en cerámica popular turolense”, Teruel, 66, Teruel, pp. 175-180.

AZUAR RUIZ, R. (1985): Castillo de La Torre Grossa (Jijona), Alicante.

AZUAR RUIZ, R. et alii. (1994): El castillo del Río (Aspe, Alicante). Arqueología de un asentamiento andalusí y la transición al feudalismo (siglos XI-XIII), Alicante.

AZUAR RUIZ R. et alii. (1995): "Cerámica tardoandalusí del País Valenciano (Primera mitad del siglo XIII)", Actas del V Coloquio internacional de la cerámica medieval del Mediterráneo Occidental, Rabat 1991, Rabat, pp. 140-161.

AZUAR RUIZ, R., MARTÍ, J. y PASCUAL, J. (1999): "El castell d'Ambra (Pego, Alicante). De las producciones andalusíes a las cerámicas de la conquista feudal (s. XIII)", Arqueología y Territorio Medieval, 6, Jaén, pp. 279-301.

BAZZANA, A. (1986): "Typologie et fonction du mobilier ceramique d'une alquería musulmane à Valence aux XI et XII siècles: Santa Fe de Oliva", Actas del III Coloquio internacional de la cerámica medieval del Mediterráneo Occidental pp. 205-217.

BAZZANA, A. (1996): "Un hisn valenciano: Shun (Uxó) en la Vall d'Uixó (Castellón)", Quaderns de prehistòria i arqueologia de Castelló, 17, Castellón, pp. 455-475.

BAZZANA, A., CRESSIER, C. y GUICHARD, R. (1988): Les chateaux ruraux de l'al-Andalus, Paris.

BELTRÁN DE HEREDIA, J. (2007): "Pisa arcaica y vaixella verda al segle XIII. L'inici de la producció de Pisa decorada en verd i manganés a la ciutat de Barcelona", Quarhis, Época II, n³, Barcelona, pp. 138-158.

BIENÉS CALVO, J. J. y GARCÍA SERRANO, J. A. (1989): "Castillo de Novallas", El Moncayo. Diez años de investigaciones arqueológicas, Tarazona, pp. 151-161.

COLL, J., MARTÍ, J. y PASCUAL, J. (1998): Cerámica y cambio cultural. El tránsito de la Valencia islámica a la cristiana, Valencia.

ESCRICHE JAIME, C. y ORTEGA ORTEGA, J. (2002): "Fichas catalográficas", ... Operis terre turolii. La cerámica bajomedieval en Teruel, Catálogo de la exposición, Museo de Teruel, Teruel, pp. 211-375.

GALLARDO CARRILLO, J. y GONZÁLEZ BALLESTEROS, J. A. (2008): "El castillo de Lorca en el siglo XIII a partir de las excavaciones arqueológicas", Alberca, 6, Murcia, pp. 113-154. 
GARCÍA PORRAS, A. (2003): "La pérdida paulatina de la identidad islámica en la primera cerámica valenciana decorada en azul y dorado. Una aproximación inicial", Cerámicas islámicas y cristianas a finales de la Edad Media. Influencias e intercambios, Granada 2003, Granada, pp. 277-299.

GARGALLO MOYA, A. (1997): El concejo de Teruel en la Edad Media (1177-1327), Teruel.

GUINOT i RODRIGUEZ, E. (1997): "La Corona de Aragón en la segunda mitad del siglo XII: Apuntes generales sobre una sociedad feudal en construcción", Studium, Revista de Humanidades, 3, Homenaje al profesor Antonio Gargallo Moya, t. I, Teruel, pp. 159-170.

GUINOT i RODRIGUEZ, E. (2009): "The expansion of a European feudal monarchy during the 13th Century: the Catalan-Aragonese Crown and the consequences of the conquest of the kingdoms of Majorca and Valencia, Catalan Historical Review, 2, Barcelona, pp. 33-47.

GUTIERREZ GONZÁLEZ, F. J. y DE MIGUEL MILLÁN, C. (2010): "La cerámica del arrabal meridional de Zaragoza durante la Edad Media", Actas de las I Jornadas de Arqueología Medieval en Aragón. Balances y novedades, Museo de Teruel 2006, Teruel, pp. 427-460.

IBAÑEZ GONZÁLEZ, J. (2010), "La arqueología urbana del Teruel medieval y moderno: resultados y visión crítica", Actas de las I Jornadas de Arqueología Medieval en Aragón. Balances y novedades, Teruel 2006, Teruel, pp. 289-332.

HERVÁS HERRERA, M. A. y RETUERCE VELASCO, M. (2001): "Hallazgos arqueológicos en la morería de Ágreda ", V Congreso de arqueología medieval española, t. II, Valladolid 1999, Valladolid, pp. 897-911.

HERNÁNDEZ PARDOS, A. (2010): Una sociedad en (trans) formación. Estudio de los repertorios cerámicos bajomedievales del Castillo de Albarracín y Plaza de la Judería de Teruel, inédito.

HERNÁNDEZ PARDOS, A. (2011): La cultura material en la plaza de la judería de Teruel: morfología urbana, sistemas constructivos y ajuar cerámico. Una aproximación desde la minoría al proceso de consolidación de la sociedad feudal, inédito.

HERNÁNDEZ PARDOS, A. (en prensa): "La mirada arqueológica bajo la plaza de la Judería de Teruel: una aproximación a su cultura material", Teruel.

HERNÁNDEZ PARDOS, A. y FRANCO CALVO, J. G. (2010): "Albarracín medieval: arqueología urbana en los últimos años", Actas de las I Jornadas de Arqueología Medieval en Aragón. Balances y novedades, Teruel 2006, Teruel, pp. 357-402.

HUERTAS ARROYO, J. (2008): "La pisa arcaica i el conjunt ceràmic associat als primers moments del convent de Santa Caterina", Quarhis, Época II, no 4, Barcelona, pp. 106-114.

LÓPEZ ELUM, P. (1984): Los orígenes de la cerámica de Manises y Paterna (1285-1335), Valencia.
LÓPEZ ELUM, P. (2002): "Los utensilios de cocina y mesa en la Baja Edad Media: Ios materiales empleados en su fabricación", Saitabi, 51-52, Valencia, pp. 105-112.

LÓPEZ ELUM, P. y COLL CONESA, J. (2006), La producción cerámica de lujo en la Baja Edad Media: Manises y Paterna. Los materiales de los recipientes para uso alimentario: su evolución y cambios según los inventarios notariales, Valencia.

LÓPEZ GARCÍA, I. et alii. (1994): Hallazgos arqueológicos en el Palau de Les Corts, Valencia.

LORIENTE A, y OLIVER, A. (ed.) (1992): L'antic Portal de Magdalena, Monografies d'Arqueologia Urbana, no 4, Lleida.

MACÍAS SOLÉ, J. M., MENCHÓN BES, J. i MUÑOZ MELGAR, A. (1997): "Cerámiques medievals a Tarragona. Aproximació al seu coneixement”, Cerámica medieval catalana, Barcelona, pp. 71-88.

MARTí, J. (1999): "Una manufactura a la búsqueda de paternidad. Apuntes sobre el inicio de la producción de cerámica decorada bajomedieval en el área valenciana y dentro del contexto del mediterráneo occidental", Atti XXXI Convengo Internazionale della Ceramica, Albisola 1998, pp. 195-206.

MARTí J. y PASCUAL, J. (1998): "La investigación sobre la cerámica bajomedieval valenciana: relectura de una bibliografía centenaria", Cerámica Medieval i Postmedieval, Monografies d'Arqueologia Medieval i Postmedieval, no 4, Barcelona, pp. 133-144.

MARTÍ, J., PASCUAL, F., y ROCA, J. (2007): "Entre el "know how" y el mercado. El horizonte cerámico de la colonización feudal en el territorio valenciano", La cerámica en entornos urbanos y rurales en el Mediterráneo occidental, Ceuta 2004, Ceuta, pp. 79-157.

MARTINEZ GARCÍA, F. J. (1991): "El Otero del Cid o Cerro Torrecid: Enclave militar del Campeador en el valle del Jalón", Simposio Internacional El Cid en el Valle del Jalón, Calatayud 1989, Calatayud, pp. 47-93.

MESQUIDA GARCÍA, M. (2004): Las ollerías de Paterna. Tecnología y producción. Vol. I. Siglos XII-XIII, Paterna.

ORTEGA ORTEGA, J. (2002): "Producción artesanal, transferencias comerciales y reproducción doméstica en Teruel durante la Baja Edad Media (ss. XIII-XV)", ... Operis terre turolii. La cerámica bajomedieval en Teruel, Museo de Teruel, Teruel, pp. 11-188.

ORTEGA ORTEGA, J. (2007a): "Anatomía del esplendor: Poder, cultura material y procesos de urbanización en Albarracín durante la Edad Media (ss. X-XIV)", Fondos de la sala de Historia Medieval del Museo de Albarracín, Albarracín, pp. 17-122.

ORTEGA ORTEGA, J. (2007b): "Fichas catalográficas", Fondos de la sala de Historia Medieval del Museo de Albarracín, Albarracín, pp. 123-342

ORTEGA ORTEGA, J. y GUTIERREZ GONZALEZ, F. J. (2006): "La cerámica medieval desde el lado de la demanda. Sobre el comercio y consumo cerámicos en la Zaragoza bajomedieval. El ejemplo del Teatro Fleta", Kalathos, 24-25, Teruel, pp. 397-421. 
ORTIZ PALOMAR, Ma. E. y PAZ PERALTA, J. A. (1995): "La cerámica gris del castillo de los calatravos (Alcañiz, Teruel)", Al-Quannis, 3-4, Alcañiz, pp. 153-168.

PASCUAL, J. y MARTÍ. J. (1987): "Nuevos datos para el estudio de la cerámica valenciana del siglo XIV", II Congreso de arqueología medieval española, t. III, Huesca, pp. 599-612.

RODRIGUEZ DEL MAZO, R. y GIBELLO BRAVO, V. (2010), "Excavación arqueológica en el solar situado entre las calles Bajo los Arcos y Mosén Peras, Teruel", Actas de las I Jornadas de Arqueología Medieval en Aragón. Balances y novedades, Teruel 2006, Teruel, pp. 461-480

ROSSELLÓ MESQUIDA, M. y LERMA ALEGRÍA, J. V. (1999): "El "Vall Vell" de Valencia. Un registro cerámico excepcional de los siglos XIII-XIV", Arqueología y Territorio Medieval, 6, Jaén, pp. 303-319.
TORRÓ ABAD, J. (1999): El naixement d'una colònia. Dominació y resistència a la frontera valenciana (12381276), Valencia.

TORRÓ ABAD, J. (2003): "Arqueologia de la conquista. Registre material, substitució de poblacions i transformació de l'espai rural valencià (segles XIII-XIV), El feudalisme comptat i debaut, Valencia, pp. 153-200.

TURINA, A. (2001): "Nuevos datos sobre la cerámica mudéjar en el centro peninsular", V Congreso de arqueología medieval española, t. II, Valladolid 1999, Valladolid, pp. 801-822. 